\title{
Distribution and Function of HCN Channels in the Apical Dendritic Tuft of Neocortical Pyramidal Neurons
}

\author{
Mark T. Harnett, ${ }^{1}$ Jeffrey C. Magee, ${ }^{1}$ and Stephen R. Williams ${ }^{2}$ \\ ${ }^{1}$ Howard Hughes Medical Institute, Janelia Farm Research Campus, Ashburn, Virginia 20147, and ${ }^{2}$ Queensland Brain Institute, The University of \\ Queensland, Brisbane QLD 4072, Australia
}

The apical tuft is the most remote area of the dendritic tree of neocortical pyramidal neurons. Despite its distal location, the apical dendritic tuft of layer 5 pyramidal neurons receives substantial excitatory synaptic drive and actively processes corticocortical input during behavior. The properties of the voltage-activated ion channels that regulate synaptic integration in tuft dendrites have, however, not been thoroughly investigated. Here, we use electrophysiological and optical approaches to examine the subcellular distribution and function of hyperpolarization-activated cyclic nucleotide-gated nonselective cation (HCN) channels in rat layer 5B pyramidal neurons. Outside-out patch recordings demonstrated that the amplitude and properties of ensemble HCN channel activity were uniform in patches excised from distal apical dendritic trunk and tuft sites. Simultaneous apical dendritic tuft and trunk whole-cell current-clamp recordings revealed that the pharmacological blockade of $\mathrm{HCN}$ channels decreased voltage compartmentalization and enhanced the generation and spread of apical dendritic tuft and trunk regenerative activity. Furthermore, multisite two-photon glutamate uncaging demonstrated that HCN channels control the amplitude and duration of synaptically evoked regenerative activity in the distal apical dendritic tuft. In contrast, at proximal apical dendritic trunk and somatic recording sites, the blockade of HCN channels decreased excitability. Dynamicclamp experiments revealed that these compartment-specific actions of HCN channels were heavily influenced by the local and distributed impact of the high density of HCN channels in the distal apical dendritic arbor. The properties and subcellular distribution pattern of HCN channels are therefore tuned to regulate the interaction between integration compartments in layer 5B pyramidal neurons.

Key words: axon; dendrite; HCN channel; neocortex; synaptic integration

\section{Introduction}

The transformation of synaptic input into action potential output is strongly influenced by the recruitment of voltage-gated ion channels, which are distributed throughout the neuronal membrane in cell-class- and dendritic-compartment-specific expression patterns (London and Häusser, 2005; Nusser, 2012). In many classes of central neurons, dendritic excitatory synaptic input can lead to the regenerative recruitment of voltage-gated ion channels, leading to the generation of dendritic spikes (London and Häusser, 2005). In cortical pyramidal neurons, dendritic spikes mediated by voltage-gated ion channels and excitatory synaptic mechanisms have been shown to increase the saliency of synaptic input on action potential output (Schiller et al., 2000; Williams and Stuart, 2002; Poirazi et al., 2003; Losonczy and Magee, 2006; Larkum et al., 2009; Harnett et al., 2013). Recently, such active dendritic synaptic integration has been shown to implement defined computational operations in physiologically en-

\footnotetext{
Received July 9, 2014; revised Nov. 19, 2014; accepted Nov. 25, 2014.

Author contributions: M.T.H., J.C.M., and S.R.W. designed research; M.T.H. and S.R.W. performed research; M.T.H. and S.R.W. analyzed data; M.T.H., J.C.M., and S.R.W. wrote the paper.

This work was supported by the Australian Research Council (Grants FT100100502 and DP130101630), the National Health and Medical Research Council (Grant APP1004575), and the Howard Hughes Medical Institute. The authors declare no competing financial interests.

Correspondence should be addressed to Dr. Stephen R. Williams, The Queensland Brain Institute, The University of Queensland, Brisbane, QLD 4072, Australia. E-mail: srw@uq.edu.au.

DOI:10.1523/JNEUROSCI.2813-14.2015

Copyright $\odot 2015$ the authors $\quad 0270-6474 / 15 / 351024-14 \$ 15.00 / 0$
}

gaged neuronal circuits (Lavzin et al., 2012; Xu et al., 2012; Sivyer and Williams, 2013; Smith et al., 2013; Palmer et al., 2014). Notably, in the apical dendritic tuft of layer 5B pyramidal neurons, widespread apical dendritic tuft electrogenesis has been found to underlie the computation of object location in the rodent somatosensory neocortex during behavior (Xu et al., 2012; Harnett et al., 2013). However, little information is available on the properties and distribution of the voltage-gated ion channels that shape the integrative operations of the apical dendritic tuft of neocortical pyramidal neurons.

One class of ion channel likely to regulate apical dendritic tuft excitability are hyperpolarization-activated cyclic nucleotidegated nonselective cation ( $\mathrm{HCN}$ ) channels. Functionally, HCN channels strongly regulate the membrane potential and resting conductance of pyramidal neurons to control the integration of excitatory and inhibitory dendritic synaptic input (Magee, 1998; Stuart and Spruston, 1998; Magee, 1999; Williams and Stuart, 2000; Berger et al., 2001; Williams and Stuart, 2003; Kole et al., 2007; Tsay et al., 2007; George et al., 2009). Antibody staining has shown a highly polarized and dense distribution of HCN channels in the distal apical dendritic tree of cortical pyramidal neurons (Santoro et al., 1997; Lörincz et al., 2002; Atkinson and Williams, 2009; Piskorowski et al., 2011), a distribution pattern confirmed by electrophysiological measurement from the apical dendritic trunk of pyramidal neurons (Magee, 1998; Williams and Stuart, 2000; Berger et al., 2001; Kole et al., 2006; Atkinson 
and Williams, 2009). Furthermore, immunogold labeling of channel isoforms has demonstrated that $\mathrm{HCN}$ channels are distributed at the highest density in the apical dendritic tuft of hippocampal subicular pyramidal neurons (Lörincz et al., 2002).

Consistent with a role for HCN channels in the control of dendritic tuft excitability, imaging studies have shown that the genetic deletion or the pharmacological blockade of HCN channels augments dendritic tuft calcium electrogenesis in CA1 pyramidal neurons (Tsay et al., 2007). Notably, the genetic deletion of $\mathrm{HCN}$ channels enhances the engagement of cortical neurons in network operations by promoting the induction of synaptic plasticity, controlling place and grid cell size, and augmenting seizure susceptibility (Nolan et al., 2004; Santoro et al., 2010; Giocomo et al., 2011; Hussaini et al., 2011). Despite the important role that active dendritic tuft integration plays in neuronal computations in the neocortical network (Xu et al., 2012; Harnett et al., 2013; Palmer et al., 2014), the distribution and function of native HCN channels in the apical dendritic tuft of neocortical pyramidal neurons has not been investigated. Here, we use direct electrophysiological recording and optical approaches to describe the distribution of HCN channels and their functional role in controlling the excitability of the apical dendritic tuft of layer 5B pyramidal neurons.

\section{Materials and Methods}

Coronal brain-slices containing the somatosensory cortices were prepared from 5- to 7-week-old male Wistar rats following University and Institutional guidelines using methods described previously in detail (Harnett et al., 2013). Individual slices were placed in a recording chamber perfused with a solution containing the following (in mM): $125 \mathrm{NaCl}$, $25 \mathrm{NaHCO}_{3}, 1.25 \mathrm{NaH}_{2} \mathrm{PO}_{4}, 3 \mathrm{KCl}, 2$ or $1.3 \mathrm{CaCl}_{2}, 1.0 \mathrm{MgCl}_{2}, 25$ glucose, $3 \mathrm{Na}$-pyruvate saturated with $95 \% \mathrm{O}_{2}, 5 \% \mathrm{CO}_{2}$ at $35-37^{\circ} \mathrm{C}$. Whole-cell recordings were made from thick-tufted layer $5 \mathrm{~B}$ pyramidal neurons with BVC-700A (Dagan) amplifiers in "bridge" mode and the electrode capacitance carefully compensated. For multisite recordings, standard wall-filamented glass pipettes (Warner Instruments) had an open tip resistance of 3-6 $\mathrm{M} \Omega$ for somatic recordings and 10-12 $\mathrm{M} \Omega$ for dendritic recordings when filled with the following (in $\mathrm{mM}$ ): 135 K-gluconate, $7 \mathrm{NaCl}, 10$ HEPES, 10 phosphocreatine, $2 \mathrm{Na}_{2}$-ATP, 0.3 $\mathrm{Na}-\mathrm{GTP}, 2 \mathrm{MgCl}_{2}$, and 0.01 Alexa Fluor 568 or 594 (Invitrogen), $\mathrm{pH}$ 7.3-7.4 with $\mathrm{KOH}$. For imaging experiments, thin walled unfilamented glass pipettes (VWR) had an open tip resistance of $4-6 \mathrm{M} \Omega$ when filled with the following (in mM): $134 \mathrm{~K}$-gluconate, $6 \mathrm{KCl}, 10 \mathrm{HEPES}, 4 \mathrm{NaCl}$, $0.3 \mathrm{Tris}_{2} \mathrm{GTP}, 4 \mathrm{Mg}_{2} \mathrm{ATP}, 14$ phosphocreatine, 0.05 Alexa Fluor 594, and 0.1 Oregon green BAPTA-6F. Two-photon imaging and glutamate uncaging were performed using a dual-galvanometer-based scanning system as described previously (Losonczy and Magee, 2006). Line scans were made at high magnification with dwell times of $8-12 \mu$ s at $150-500$ $\mathrm{Hz}$ and 3 to 12 line scans were averaged for each condition. Calcium signals were expressed as $\Delta F / F(\%)$ calculated as $\left[\left(F-F_{\text {baseline }}\right) / F_{\text {baseline }}\right] * 100$. Data were collected from dendrites that were at least $30 \mu \mathrm{m}$ (and up to $150 \mu \mathrm{m}$ ) below the surface of the slice and were not prematurely cut before termination. For fast, multisite glutamate uncaging, $10 \mathrm{~mm}$ MNI-glutamate (Tocris Bioscience) was delivered via pressure ejection to the surface of the slice while focused $720 \mathrm{~nm}$ laser light was directed to $10-30$ preselected points near spine heads ( $0.2 \mathrm{~ms}$ dwell time, $0.1 \mathrm{~ms}$ move time). All drugs were dissolved in the extracellular solution and applied by bath perfusion. 4-Ethylphenylamino-1,2-dimethyl-6-methylaminopyrimidinium chloride (ZD7288, $10 \mu \mathrm{M}$ ) was bath applied for a maximum period of 10 minutes.

Simulated synaptic potentials were generated using a real-time dynamic conductance clamp (SM1; Cambridge Conductance) with a 1090\% settling time of 290 ns (Harsch and Robinson, 2000; Williams, 2004, 2005). The dynamic conductance clamp emulated a synaptic conductance, $g(t)$, by the injection of current, $I(t)$, that depends on membrane potential, $V(t)$, and the reversal potential of the conductance, $E_{\text {rev }}$, according to the following equation:
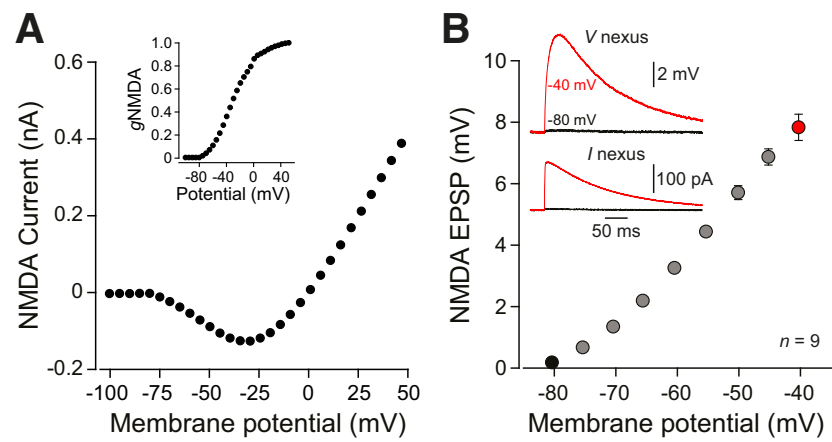

Figure 1. Voltage-dependent properties of the simulated NMDA conductance. $\boldsymbol{A}$, Steadystate current-voltage relationship of the NMDA conductance recorded from an isopotential model cell. The inset shows the conductance-voltage relationship. $\boldsymbol{B}$, Relationship between NMDA gEPSP amplitude and holding potential recorded from the nexus of the apical dendritic trunk of layer $5 B$ pyramidal neurons. The inset shows average NMDA gEPSPs recorded at the indicated holding potentials. Pooled data are shown as mean \pm SEM.

$$
I(t)=g(t)[V(t)-E r e v]
$$

The time course of an emulated AMPA conductance was determined by a double exponential driving function with a rise time constant $\left(\tau_{\text {rise }}\right)$ of $0.5 \mathrm{~ms}$ and decay time constant $\left(\tau_{\text {decay }}\right)$ of $5 \mathrm{~ms}$. For all emulated synaptic conductance changes, $E_{\text {rev }}$ was set to $0 \mathrm{mV}$. The emulated NMDA conductance change exhibited a voltage dependence that mimicked those observed experimentally (Nowak et al., 1984; Jahr and Stevens, 1990; Harsch and Robinson, 2000), a process described by the following equation:

$$
I(t)=\frac{g(t)[V(t)-E r e v]}{1+K 1 \exp (-K 2(V(t))}
$$

Where $\mathrm{K} 1$ and $\mathrm{K} 2$ are constants that determined the voltage dependence of the emulated NMDA conductance (Harsch and Robinson, 2000). The emulated NMDA conductance exhibited a voltage of half-maximal activation of $-29 \mathrm{mV}$ and a steepness coefficient of -16 when approximated by a single Boltzmann function, which was voltage dependent, yielding a characteristic U-shaped steady-state current-voltage relationship when injected to a model cell recorded under voltage-clamp conditions (Fig. $1 A$ ) These properties ensured that voltage responses produced by a fast rising $\left(\tau_{\text {rise }}=0.5 \mathrm{~ms}\right)$, slowly decaying $\left(\tau_{\text {decay }}=150 \mathrm{~ms}\right)$ simulated NMDA conductance change at the nexus of the apical dendritic trunk of layer 5 pyramidal neurons were voltage dependent (Fig. $1 B ; n=9, n=9$ slices, $n=6$ animals; recorded in ZD8288 $10 \mu \mathrm{M}$ ), consistent with previous analysis of layer 5 to layer 5 unitary EPSPs (Markram et al., 1997; Wang et al., 2008). In all reported somatic, apical dendritic trunk, and nexus recordings, dynamic conductance clamp EPSPs (gEPSPs) were generated using closely spaced $(<10 \mu \mathrm{m})$ electrodes for independent current injection and voltage recording, whereas a single electrode (access resistance $<30 \mathrm{M} \Omega$ ) was used at apical dendritic tuft sites. Linear AMPA and voltage-dependent NMDA conductance changes were generated independently and the injected current summed. In some experiments, an additional linear leak conductance was generated at the nexus with a reversal potential set to $-30 \mathrm{mV}$ or the resting potential recorded in ZD7288. The voltage threshold of dendritic spike initiation in response to steps of ideal current was measured at the steady-state voltage $>200 \mathrm{~ms}$ after the termination of an isolated dendritic spike (Harnett et al., 2013). Current and voltage signals were low-pass filtered (dc to 10 $\mathrm{kHz}$ ) and acquired at $30-50 \mathrm{kHz}$.

Outside-out patches were excised from apical dendritic sites using pipettes of similar open tip resistance (10 to $12 \mathrm{M} \Omega$ ) filled with the following (in mM): $130 \mathrm{~K}$-gluconate, $7 \mathrm{NaCl}, 10 \mathrm{HEPES}, 2 \mathrm{Na}_{2}$-ATP, 0.3 Na-GTP, $2 \mathrm{MgCl}_{2}$, and 5 ethylene glycol-bis(b-aminoethylether)$\mathrm{N}, \mathrm{N}, \mathrm{N}^{\prime}, \mathrm{N}^{\prime}$-tetraacetic acid, $\mathrm{pH}$ 7.3-7.4 with $\mathrm{KOH}$. The extracellular solution was supplemented with tetrodotoxin $(1 \mu \mathrm{M})$ and maintained at room temperature $\left(26-26.5^{\circ} \mathrm{C}\right)$ or heated to $35-36^{\circ} \mathrm{C}$. When the reversal 
A

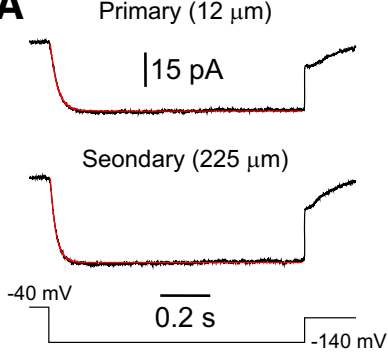

B

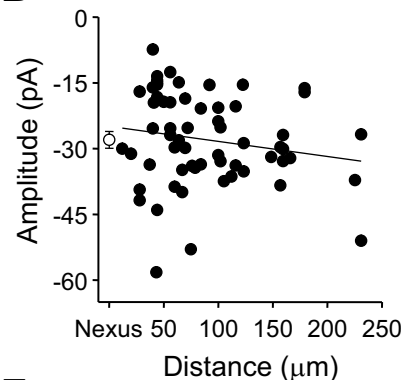

E

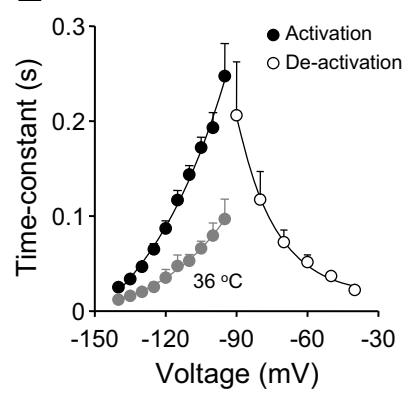

$F$

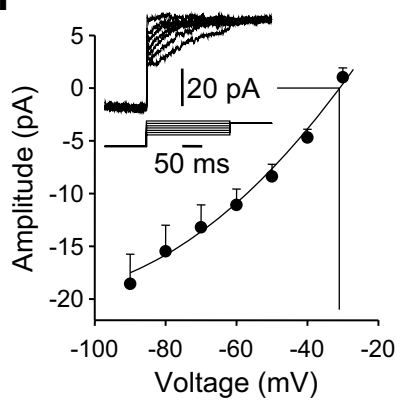

C

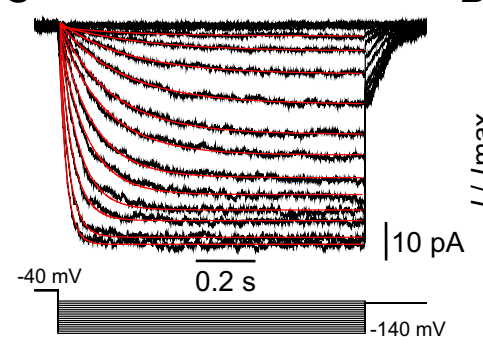

G

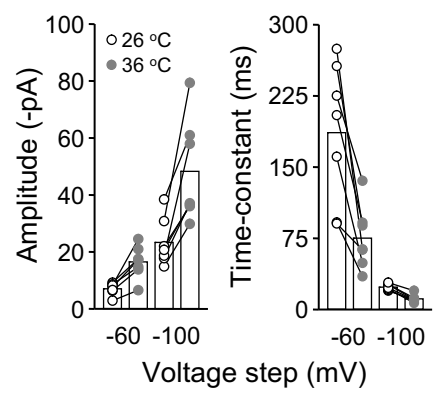

D

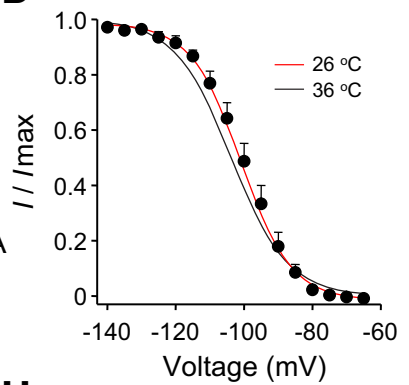

H

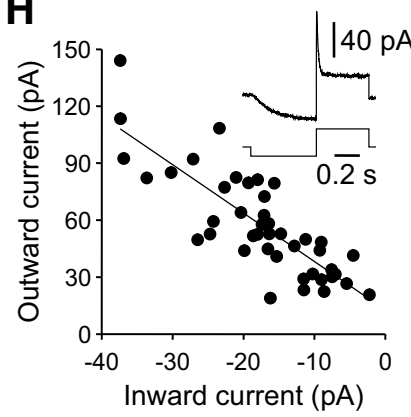

Figure 2. Properties and distribution of HCN channels in the apical dendritic tuft. $\boldsymbol{A}$, Averaged leak subtracted ensemble HCN channel activity recorded in outside-out patches excised from the indicated primary and secondary apical dendritic tuft sites (distance measured from the nexus of the apical dendritic trunk). The red lines represent single exponential fits to the activation of ensemble HCN channel activity. The lower trace shows the voltage test step. $\boldsymbol{B}$, Steady-state amplitude of HCN channel activity recorded from patches excised from the nexus (open symbol, mean \pm $\mathrm{SEM}, n=30$ ) and apical dendritic tuft sites (filled symbols). The continuous line represents the results of linear regression analysis of apical dendritic tuft data. $C, A$ family of ensemble HCN channel currents recorded from a patch excised $159 \mu \mathrm{m}$ from the nexus generated in response to an incremental series of negative voltage steps (lower overlain traces). The red lines represent single exponential fits to the activation of ensemble HCN channel activity. D. Activation curve of ensemble HCN channel activity measured from tail currents. The red continuous line represents a single Boltzmann function fit to the data. The black line represents a single Boltzmann function fit to data obtained at physiological temperatures. $\boldsymbol{E}$. Voltage dependence of the kinetics of activation (filled symbols) and deactivation (open symbols) of ensemble HCN channel activity. The gray symbols show the activation kinetics at physiological temperature. Continuous lines represent fits to the data by single exponential functions. $\boldsymbol{F}$, Reversal potential of $\mathrm{HCN}$ tail currents. Data were fit by a second-order polynomial function (continuous line). The drop lines show the reversal potential. The inset shows the voltage dependence of tail currents in a tuft patch excised $220 \mu \mathrm{m}$ from the nexus. G, Temperature dependence of the steady-state amplitude and activation kinetics of ensemble channel activity evoked in response to the indicated voltage steps at room and physiological temperatures. $\boldsymbol{H}$, Coexpression of HCN and voltage-activated potassium channels in patches excised from the apical dendritic tuft. The inward HCN current was measured just before the termination of a negative voltage step, and the outward potassium current at peak amplitude. The line is the result of linear regression analysis. The inset shows a representative sequence of ensemble $\mathrm{HCN}$ and potassium channel activity in a patch excised $179 \mu \mathrm{m}$ from the nexus. Pooled data are shown as mean \pm SEM.

potential of ensemble HCN channel activity was investigated the extracellular solution included the voltage-gated potassium $\left(K_{\mathrm{V}}\right)$ channel blocker quinidine ( $25 \mu \mathrm{M})$ (Harnett et al., 2013). Ensemble HCN channel activity was recorded using a Multi-Clamp 700 amplifier (Molecular Devices), electrode capacitance was compensated, and currents were low-pass filtered (dc to $5 \mathrm{kHz}$ ). To map channel density, ensemble HCN channel activity was generated in response to a $-100 \mathrm{mV}(1 \mathrm{~s})$ test step interleaved by the repetition of $51 / 10$ scaled voltage pulses for online or offline leak subtraction from an intrapipette holding potential of -40 $\mathrm{mV}$. Measurements were made from digital averages of $>20$ consecutive trials. After gathering ensemble channel data, a whole-cell recording was obtained at the same apical dendritic site and the neuron was dialyzed with Alexa Fluor 568 or 594 to record morphology.

\section{Results}

\section{$\mathrm{HCN}$ channel distribution in the apical dendritic tuft}

The subcellular distribution of native HCN channels has been examined using cell-attached recording techniques from largediameter trunk dendrites of several neuronal classes (Magee, 1998; Williams and Stuart, 2000; Berger et al., 2001; Kole et al., 2006; Angelo et al., 2007). We have previously observed that the properties of ensemble $\mathrm{HCN}$ channel activity recorded in cellattached patches are subject to severe distortion because of the generation of trans-membrane voltage changes, a problem that is exaggerated in recordings made from neurons and neuronal processes with high apparent input resistance (Williams and Wozny, 2011). Because the apparent input resistance is recording-site dependent in neocortical pyramidal neurons (Harnett et al.,
2013), we used cell-free patch-clamp recording techniques to examine the distribution of HCN channels. Ensemble channel activity was recorded in outside-out patches excised from distal apical dendritic sites of layer $5 \mathrm{~B}$ pyramidal neurons of the rat somatosensory neocortex under visual guidance (Fig. 2). For patches excised from the base of the apical dendritic tuft, referred to as the nexus of the apical dendritic trunk, a negative voltage test step $(-100 \mathrm{mV}, 1 \mathrm{~s}$; from an intrapipette holding voltage of -40 $\mathrm{mV}$ ) generated a slowly activating, non-inactivating inward current, with an average steady-state amplitude of $-28.0 \pm 1.9 \mathrm{pA}$ ( $n=30$ patches, $n=24$ cells, $n=11$ animals). A similar pattern of activity was recorded from patches excised from apical dendritic tuft branches up to $231 \mu \mathrm{m}$ from the nexus, with pooled data showing a uniform steady-state amplitude across the tuft (Fig. $2 A, B$; steady-state amplitude $=-28.0 \pm 1.4 \mathrm{pA}$; slope of linear regression $=-3.4 \mathrm{pA} / 100 \mu \mathrm{m} ; n=61$ patches, $n=50$ cells, $n=13$ animals). When the HCN channel blocker ZD7288 $10 \mu \mathrm{M}$ (Harris and Constanti, 1995; Williams and Stuart, 2000; Kole et al., 2006) was added to the bath solution, the amplitude of ensemble channel activity evoked by the $-100 \mathrm{mV}$ test step was significantly reduced, indicating that the slow inward current is mediated by HCN channels (data not shown; control $=-28.9 \pm$ $5.8 \mathrm{pA}$; ZD7288 $=-2.8 \pm 1.2 \mathrm{pA} ; n=7, n=7$ slices, $n=6$ animals; paired $t$ test: $\mathrm{T}=4.479 ; p=0.0042$ ).

The activation properties of tuft HCN channels were voltage dependent. In response to an incremental series of negative volt- 
age steps, the amplitude of ensemble channel activity increased and the activation time course accelerated with membrane hyperpolarization (Fig. 2C). Analysis of tail currents revealed a sigmoidal activation curve, which could be fit with a single Boltzmann function with a voltage of half-maximal activation of $-100.6 \pm 1.9 \mathrm{mV}$ and a steepness coefficient of $6.4 \pm 0.3$ (Fig. $2 D ; n=11$ patches, $n=11$ cells, $n=8$ animals). The time course of ensemble HCN activation could be well approximated by a single exponential process throughout the activation voltage range, which sped from $247 \pm 34 \mathrm{~ms}$ at $-90 \mathrm{mV}$ to $25 \pm 2 \mathrm{~ms}$ at $-140 \mathrm{mV}$ (Fig. 2E). Similarly, the time course of HCN channel deactivation was voltage dependent, accelerating from $206 \pm 56$ $\mathrm{ms}$ at $-90 \mathrm{mV}$ to $22 \pm 3 \mathrm{~ms}$ at $-40 \mathrm{mV}$ (Fig. $2 E$ ). Thus the voltage-dependent properties of HCN channels in the apical dendritic tuft are similar to those previously reported from more proximal dendritic sites in layer $5 \mathrm{~B}$ pyramidal neurons (Williams and Stuart, 2000; Berger et al., 2001; Kole et al., 2006; Kole et al., 2007; Atkinson and Williams, 2009).

Excised patch recordings allowed determination of the reversal potential and the temperature dependence of $\mathrm{HCN}$ channel gating. Analysis of tail currents revealed that the reversal potential of ensemble $\mathrm{HCN}$ channel activity was $-30.7 \pm 1.6 \mathrm{mV}$ (Fig. $2 F$; $n=8$ patches, $n=8$ slices, $n=6$ animals). The activation properties of HCN channels were highly temperature dependent (Fig. $2 E, G)$. In each patch tested, the steady-state amplitude of ensemble $\mathrm{HCN}$ channel activity increased (Fig. $2 G ; 26.1 \pm 0.3^{\circ} \mathrm{C}:-100$ $\mathrm{mV}$ test step $=-23.3 \pm 3.1 \mathrm{pA} ; 35.9 \pm 0.1^{\circ} \mathrm{C}=-48.3 \pm 6.9 \mathrm{pA}$; $n=7$; paired $t$ test: $\mathrm{T}=4.873 ; p=0.0028$ ) and the activation time constant accelerated with increasing temperature (Fig. $2 G$; $26.1 \pm 0.3^{\circ} \mathrm{C}:-100 \mathrm{mV}$ test step $=23.6 \pm 1.3 \mathrm{~ms}, 35.9 \pm 0.1^{\circ} \mathrm{C}=$ $11.3 \pm 1.5 \mathrm{~ms} ; n=7$; paired $t$ test: $\mathrm{T}=12.21 ; p<0.0001)$. Pooled data revealed that these effects were unrelated to changes in the voltage dependence of ensemble HCN channel activation (Fig. $2 D$, black line). The steady-state amplitude of ensemble HCN channel activity therefore increases with a $Q_{10}$ of $\sim 2.2$, a value considerably greater than the $\mathrm{Q}_{10}$ of $\sim 1.2-1.5$ determined for conductance of other classes of voltage-gated channels (Hodgkin et al., 1952; Beam and Donaldson, 1983; Milburn et al., 1995), a disparity that may reflect the unique structure of HCN channels (Zagotta et al., 2003) and/or the cooperativity of channel activation (Dekker and Yellen, 2006). Together, these data reveal a uniform $\mathrm{HCN}$ conductance throughout the apical dendritic tuft of layer 5B pyramidal neurons, with an average density of $56.5 \pm$ $2.7 \mathrm{pS} \mu \mathrm{m}^{-2}$ at tuft sites and $56.6 \pm 3.9 \mathrm{pS} \mu \mathrm{m}^{-2}$ at the nexus of the apical dendritic trunk (calculated assuming a patch area of 4.5 $\mu \mathrm{m}^{2}$ (Engel and Jonas, 2005) and an experimentally determined reversal potential of $-30 \mathrm{mV}$ ). Based on previous estimates of the single channel conductance of HCN channels (Kole et al., 2006), we conservatively estimate that a uniform density of $\sim 85 \mathrm{HCN}$ channels $\mu \mathrm{m}^{-2}$ are expressed throughout the apical dendritic tuft.

We next investigated whether apical dendritic tuft HCN channels are coexpressed with other classes of voltage-gated channels. In each patch, we examined both $\mathrm{HCN}$ and $K_{\mathrm{V}}$ channels, activating $\mathrm{HCN}$ channels in response to negative intrapipette voltage steps $(-40 \mathrm{mV}, 500 \mathrm{~ms}$ from an intrapipette holding voltage of $-60 \mathrm{mV})$, and $K_{\mathrm{V}}$ channels in response to positive steps $(100 \mathrm{mV}$, $400 \mathrm{~ms}$ from an intrapipette holding voltage of $-60 \mathrm{mV}$; Fig. $2 \mathrm{H})$. Pooled data showed a steep linear correlation between the steady-state amplitude of ensemble HCN channel activity and the peak amplitude of $K_{\mathrm{V}}$ channel activity (Fig. $2 \mathrm{H}$; correlation coefficient $=0.82$; uncorrelated probability $<0.0001 ; n=43$ patches, $n=36$ cells, $n=15$ animals). The average amplitude of ensemble $K_{\mathrm{V}}$ channel activity $($ peak $=57.1 \pm 4.2 \mathrm{pA}$; steady-state $=11.1 \pm$
$0.8 \mathrm{pA} ; n=43$ ) were not significantly different from those previously recorded in the presence of ZD7288 (Harnett et al., 2013), suggesting that, under our recording conditions, ZD7288 does not block $K_{\mathrm{V}}$ channels. HCN channels are therefore colocalized, at micrometer resolution, with $K_{\mathrm{V}}$ channels, which have been shown recently to functionally regulate the excitability of the apical dendritic tuft of layer 5B pyramidal neurons (Harnett et al., 2013).

\section{HCN channels regulate tuft excitability}

To investigate the functional role of HCN channels in the dendritic tuft, simultaneous whole-cell current-clamp recordings were made from the nexus of the apical dendritic trunk and tuft sites (Fig. 3; $n=38, n=38$ slices, $n=21$ animals). Under control conditions, voltage responses evoked by the injection of smallamplitude positive and negative current steps $(200 \mathrm{pA}, 600 \mathrm{~ms}$ duration) at tuft sites or the nexus were dominated by timedependent rectification, characterized by a depolarizing sag potential during the course of negative voltage responses and a transient depolarizing potential at the onset of positive voltage responses (Fig. $3 \mathrm{~A}, \mathrm{C}$ ). Simultaneous recording revealed the decremental distance-dependent impact of voltage responses generated by positive and negative current steps injected at increasingly remote apical dendritic tuft sites as they spread from the tuft site of generation to the nexus (Fig. $3 A, B$ ). This mirrored the attenuation pattern when current steps were injected at the nexus (Fig. $3 C, D)$. The bath application of ZD7288 $(10 \mu \mathrm{M})$ hyperpolarized the resting membrane potential at tuft and nexus recording sites (control: tuft $=-59.3 \pm 0.5 \mathrm{mV}$, nexus $=-59.0 \pm 0.5 \mathrm{mV}$; ZD7288: tuft $=-77.4 \pm 0.6 \mathrm{mV}$, nexus $=-77.4 \pm 0.6 \mathrm{mV}$ ). When the membrane potential was restored by tonic current injection through each of the recording electrodes, the steadystate amplitude of voltage responses at the tuft site of generation was increased, time-dependent rectification was removed, and the amplitude of voltage responses that spread to the nexus recording site increased dramatically (Fig. $3 A, B$; tuft $=-60.3 \pm$ $0.5 \mathrm{mV}$, holding current $=0.14 \pm 0.03 \mathrm{nA}$; nexus $=-60.2 \pm 0.4$ $\mathrm{mV}$, holding current $=0.29 \pm 0.03 \mathrm{nA}$ ). Analogous results were obtained when voltage responses were generated at the apical dendritic nexus and independently recorded from the tuft (Fig. $3 C, D$ ). Pooled data revealed that ZD7288 significantly increased the voltage transfer between recording sites (Fig. $3 E$; tuft to nexus: control $=0.46 \pm 0.04 ;$ ZD7288 $=0.63 \pm 0.02$; Wilcoxon signedrank test: $p<0.0001$; nexus to tuft: control $=0.60 \pm 0.03$; ZD7288 $=0.83 \pm 0.02$; Wilcoxon signed-rank test: $p<0.0001)$ and the steady-state apparent input resistance at each site (Fig. $3 F ;-200$ pA tuft: control $=18.0 \pm 1.2 \mathrm{M} \Omega$; ZD $7288=57.5 \pm$ $2.3 \mathrm{M} \Omega$; paired $t$ test: $\mathrm{T}=23.3 ; p<0.0001 ;-200$ pA nexus: control $=12.8 \pm 0.7 \mathrm{M} \Omega ; \mathrm{ZD} 7288=45.7 \pm 2.0 \mathrm{M} \Omega$; paired $t$ test: $\mathrm{T}=19.9 ; p<0.0001)$. Furthermore, the blockade of HCN channels increased the peak amplitude and prolonged the time course of voltage responses evoked by the injection of EPSCshaped ideal current waveforms at the tuft site of generation and after their spread to the nexus, abolishing the normalization of the time course of tuft-generated voltage responses (data not shown; electrode separation $=116 \pm 7 \mu \mathrm{m}$; EPSC amplitude $=$ $200 \mathrm{pA} ; \tau_{\text {rise }}=0.5 \mathrm{~ms}, \tau_{\text {decay }}=5 \mathrm{~ms}$, voltage responses: control tuft amplitude $=4.72 \pm 0.25 \mathrm{mV}, \mathrm{ZD} 7288=6.05 \pm 0.29 \mathrm{mV}$; control tuft time course at half amplitude $=7.53 \pm 0.09 \mathrm{~ms}$, ZD7288 = $11.0 \pm 0.20 \mathrm{~ms}$; control amplitude at nexus $=2.23 \pm$ $0.12 \mathrm{mV}, \mathrm{ZD} 7288=3.06 \pm 0.12 \mathrm{mV}$; control nexus time course at half amplitude $=8.15 \pm 0.12 \mathrm{~ms}$, slope $=0.5 \mathrm{~ms} / 100 \mu \mathrm{m}$, ZD7288 $=13.57 \pm 0.20 \mathrm{~ms}$; slope $=1.6 \mathrm{~ms} / 100 \mu \mathrm{m}$; all values 

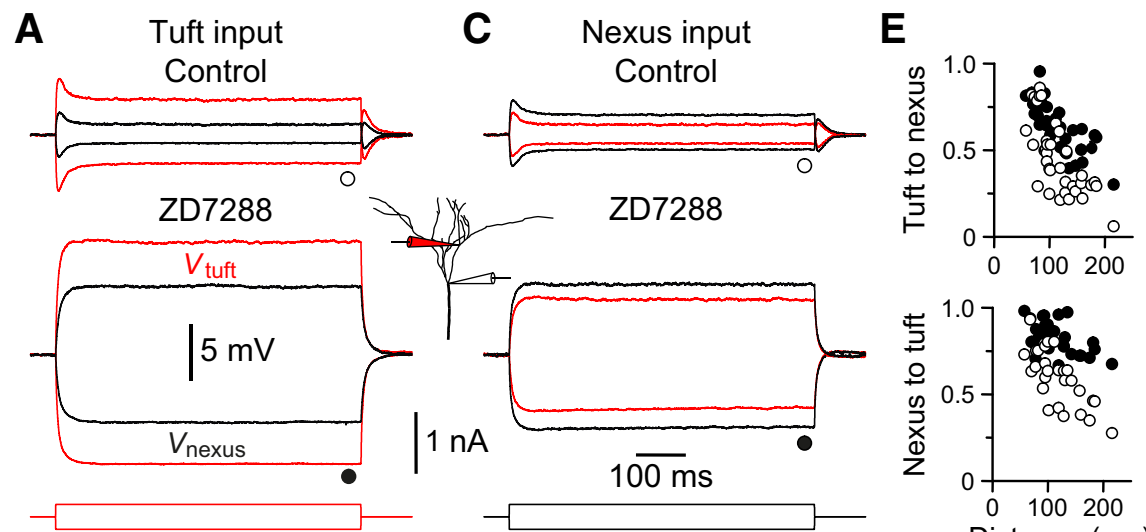

\section{G Tuft input Control}
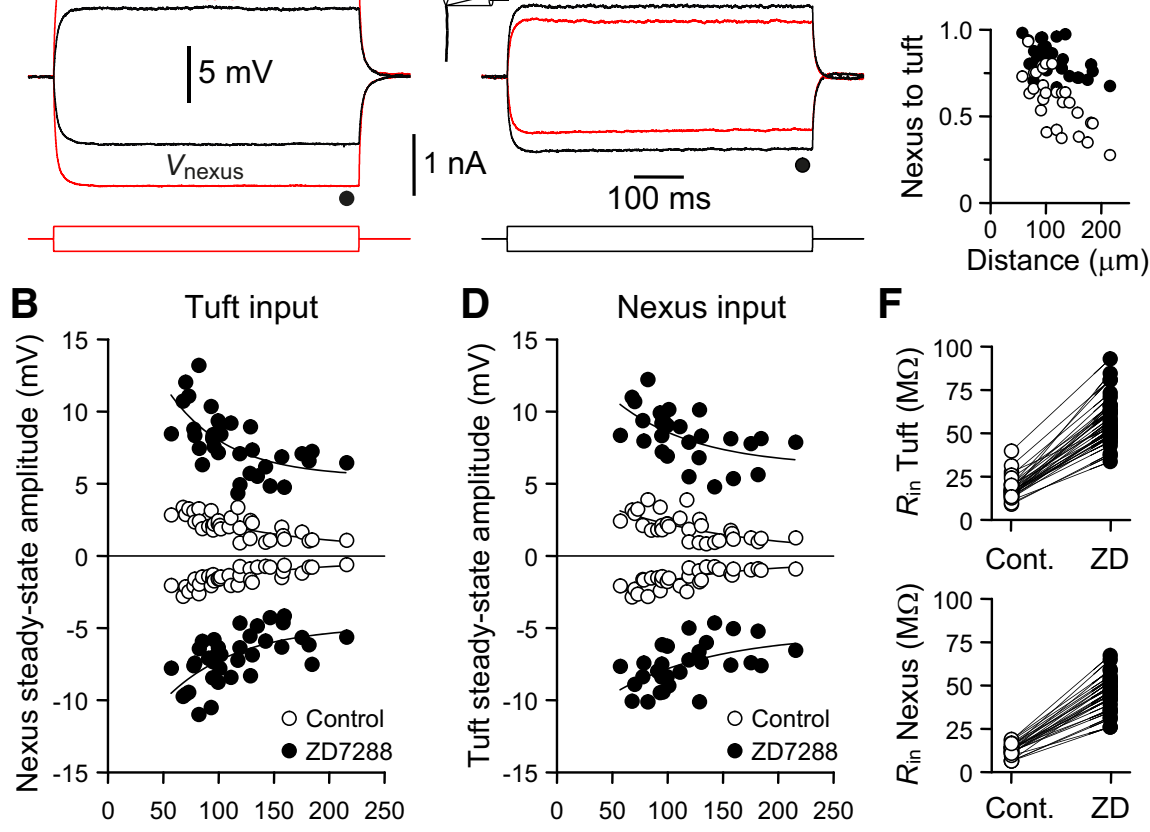

\section{$\mathbf{F}$}
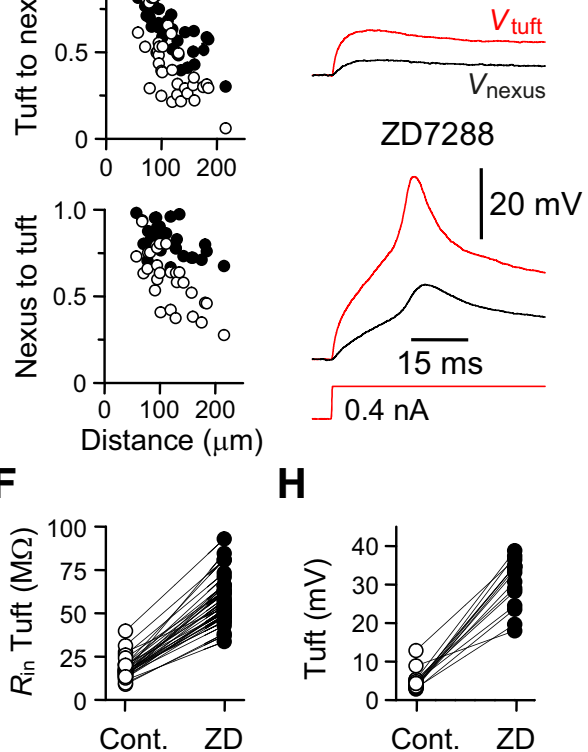

$\mathrm{H}$
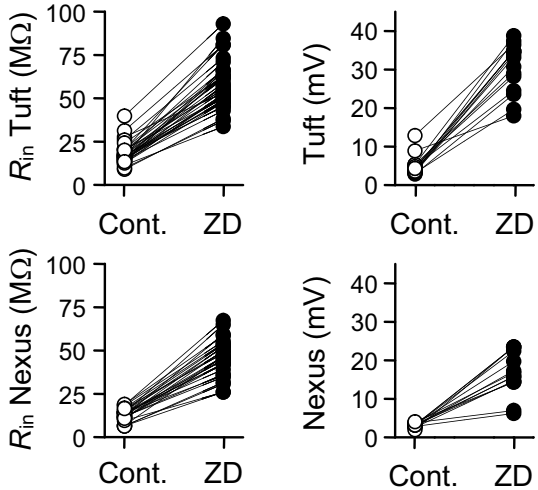

Electrode separation $(\mu \mathrm{m})$

Electrode separation $(\mu \mathrm{m})$

Figure 3. HCN channels control resting conductance and voltage attenuation in the apical dendritic tuft. $A, C, H C N$ channels regulate the amplitude and spread of voltage responses in the apical dendritic tuft. Traces illustrate voltage responses simultaneously recorded from the apical dendritic tuft (red traces, $143 \mu \mathrm{m}$ from nexus electrode) and the nexus of the apical dendritic trunk (black traces), generated in response to current steps (bottom traces) delivered to either the tuft $(\boldsymbol{A})$ or nexus ( $\boldsymbol{C}$ under control (top traces) and in ZD7288 (10 $\mu \mathrm{M}$, middle traces). The inset shows a line reconstruction of the apical dendritic tuft and the placement of recording electrodes. $\boldsymbol{B}, \boldsymbol{D}$, Pooled data illustrating the steady-state amplitude of voltage responses at the nexus $(\boldsymbol{B})$ or apical dendritic tuft $(\boldsymbol{D})$ when $200 \mathrm{pA}$ positive or negative currents steps were delivered to the apical dendritic tuft $(\boldsymbol{B})$ or nexus sites $(\boldsymbol{D})$ under control conditions (open symbols) and in ZD7288 (10 $\mu \mathrm{M}$, filled symbols). The continuous lines represent exponential fits to the data. $\boldsymbol{E}$, Impact of blocking HCN channels on the decremental transfer of voltage from tuft to nexus (top graph) and nexus to tuft (bottom graph) under control conditions (open symbols) and in ZD7288 (10 $\mu \mathrm{M}$, filled symbols). Voltage responses were generated in response to $-200 \mathrm{pA}$ current steps. $F$, Impact of blocking HCN channels (ZD) on steady-state input resistance $\left(R_{\text {in }}\right)$ at apical dendritic tuft (top graph) and nexus sites (bottom graph). $\mathbf{G}$, Blocking HCN channels unmasks tuft electrogenesis. Traces illustrate simultaneously recorded tuft (159 $\mu \mathrm{m}$ from nexus, red traces) and nexus (black traces) voltage responses evoked by a $400 \mathrm{pA}$ current step injected through the tuft electrode, under control (top traces) and in ZD7288 (10 $\mu \mathrm{m}$, bottom traces). Note the generation of a local apical dendritic tuft spike in ZD7288, when the resting membrane was repolarized to control values ( $-61 \mathrm{mV})$. $\boldsymbol{H}$, Pooled data demonstrating the augmentation of local apical dendritic spike initiation by blocking HCN channels (ZD) at the tuft site of generation (top graph), and the decremental spread to the nexus (bottom graph).

significantly different at $p<0.0001, \mathrm{~T}=6.0-27.4$, paired $t$-test; $n=32 ; n=32$ slices, $n=19$ animals). Together, these data indicate that HCN channels substantially control the local amplitude of tuft voltage responses and their impact at the nexus.

To determine the influence of HCN channels on the electrical excitability of the apical dendritic tuft, we generated voltage responses by injecting steps of positive current at tuft sites $>100$ $\mu \mathrm{m}$ from the nexus (Fig. $3 G$; distance $=140 \pm 8 \mu \mathrm{m}$; current step $=0.45 \pm 0.03 \mathrm{nA} ; n=15, n=15$ slices, $n=10$ animals). Under control conditions, positive current steps generated subthreshold tuft voltage responses crowned by a small amplitude transient depolarizing potential. However, when HCN channels were blocked and the membrane potential restored to control values, the same positive current steps reliably generated local apical dendritic tuft spikes with a voltage threshold of $-31.1 \pm$ $1.6 \mathrm{mV}$, which decrementally spread to the nexus (Fig. $3 G, H$, holding current: tuft $=0.16 \pm 0.02 \mathrm{nA}$; nexus $=0.30 \pm 0.05$ ). These data indicate that $\mathrm{HCN}$ channels regulate the excitability of the apical dendritic tuft through the control of resting conductance, but do not fully address the physiological role played by
HCN channels because the control of the membrane potential by HCN channels was compensated for (George et al., 2009). To address this directly, we investigated the control of the local amplitude and distance-dependent spread of simulated excitatory synaptic input by HCN channels.

In a passive isopotential system, the introduction of a noninactivating excitatory conductance, such as that mediated by HCN channels (reversal potential $-30 \mathrm{mV}$; Fig. $2 F$ ), will have excitatory actions at membrane potentials negative to the reversal potential of the conductance (George et al., 2009; Migliore and Migliore, 2012). Previous work suggests that the peak level of depolarization obtained by dendritic EPSPs will decrease when the HCN conductance is blocked unless EPSPs interact with other conductances (George et al., 2009; Migliore and Migliore, 2012). To test this relationship directly in the apical dendritic tuft of layer 5B pyramidal neurons, we used dynamic conductance clamp techniques to generate simulated EPSPs (referred to as gEPSPs) at determined apical dendritic tuft sites. We first analyzed the response to a simulated linear AMPA receptor-mediated excitatory postsynaptic conductance (EPSG; distance from nexus = 
A
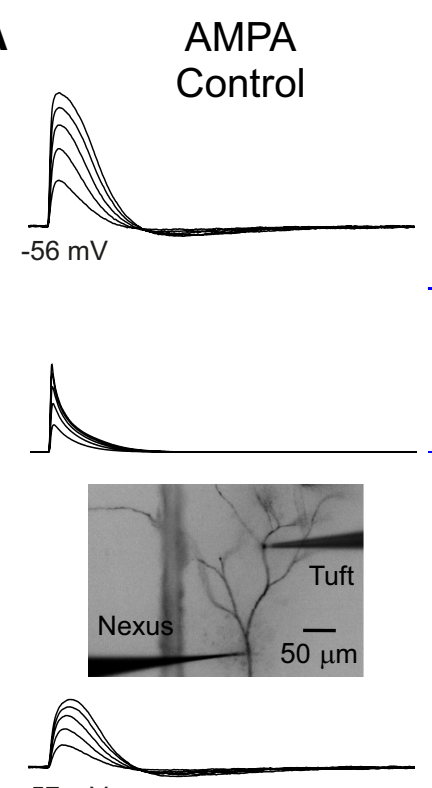

$-57 \mathrm{mV}$
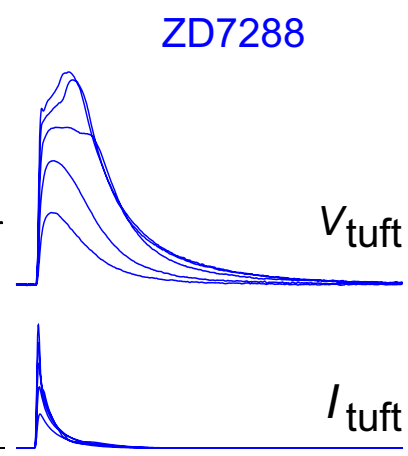

AMPA

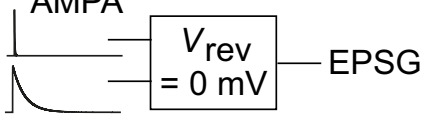

NMDA

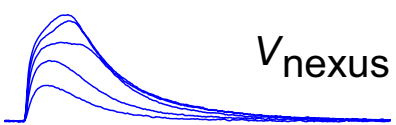

C
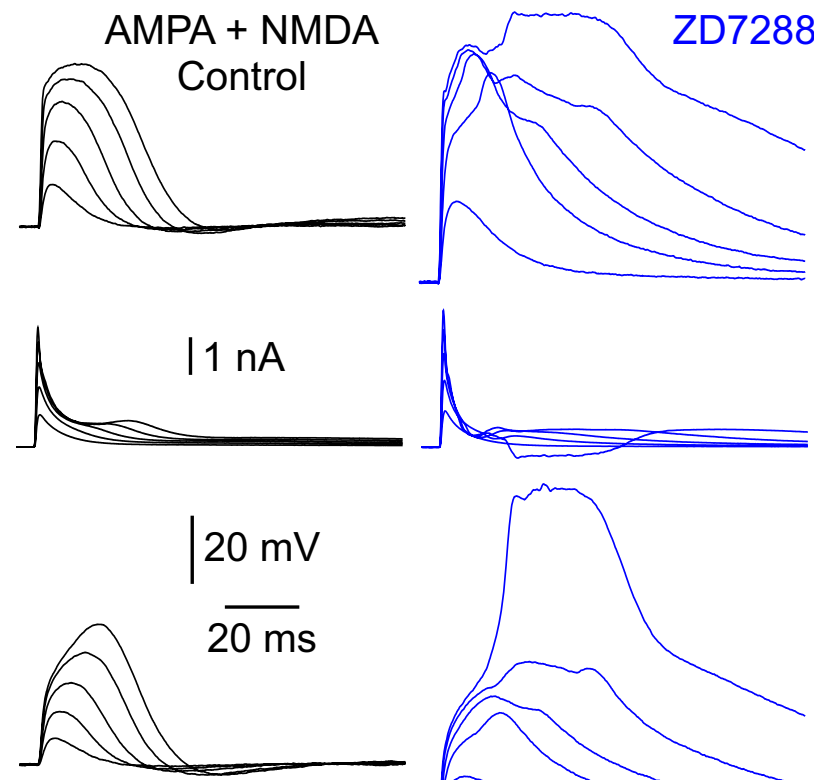

B

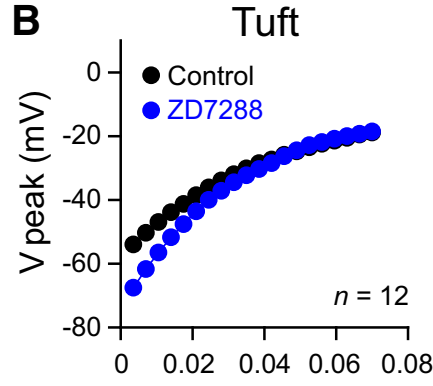

Synaptic strength $(\mu \mathrm{S})$

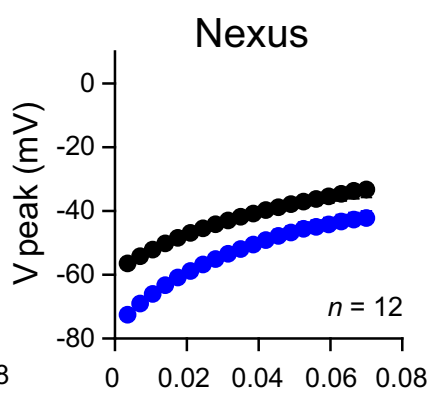

Synaptic strength $(\mu \mathrm{S})$

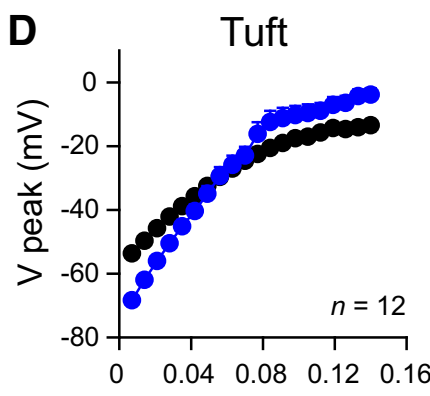

Synaptic strength $(\mu \mathrm{S})$

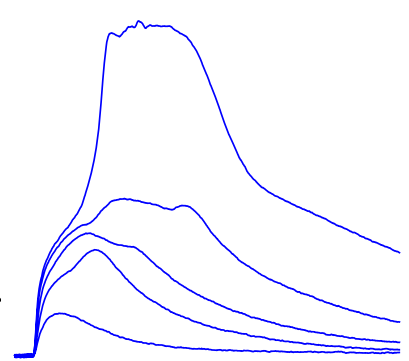

Nexus

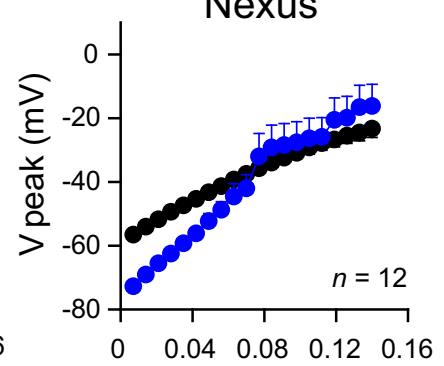

Synaptic strength $(\mu \mathrm{S})$

Figure 4. HCN channels inhibit excitatory input in the tuft. A, Simultaneous apical dendritic tuft (155 $\mu \mathrm{m}$ from the nexus electrode, top traces) and nexus (bottom traces) recording of a family of gEPSPs generated at the tuft recording site by AMPA conductance changes (middle traces), under control conditions (black) and in the presence of ZD7288 (10 $\mu \mathrm{M}$, blue traces). Note the generation of small amplitude apical dendritic tuft spikes in ZD7288. The inset shows a photomicrograph of the recorded neuron and a schematic representation of the dynamic clamp. $\boldsymbol{B}$, Pooled data illustrating the peak membrane potential ( $V$ peak) achieved by gEPSPs generated by AMPA conductance changes at the tuft site of generation (left graph) and the nexus (right graph) under control (black symbols), and ZD7288 (blue symbols). C, Tuft (top traces) and nexus (bottom traces) voltage responses generated by a family of AMPA and NMDA conductance changes (middle traces). Note the generation of both apical dendritic tuft and nexus electrogenesis in ZD7288 (blue traces), same neuron as A. D, Pooled input- output relationships under the indicated conditions generated by AMPA and NMDA conductance changes. Note the crossing of control (black) and ZD7288 (blue) input- output curves, which reflects the generation of tuft and nexus electrogenesis. Pooled data are shown as mean \pm SEM.

$105 \pm 12 \mu \mathrm{m} ; n=12, n=12$ slices, $n=9$ animals). Under control conditions, the peak voltage obtained in response to a series of increasing amplitude AMPA EPSGs injected at tuft sites was nonlinearly related to the input conductance, reaching a plateau as the local voltage approached the reversal potential (Fig. $4 A, B)$. Simultaneous recording from the nexus revealed that voltage attenuation ensured that the gEPSPs were considerably diminished as they spread from the tuft to the nexus (Fig. 4A,B). Blockade of HCN channels with ZD7288 $(10 \mu \mathrm{M})$ caused membrane potential hyperpolarization, yet large amplitude gEPSPs reached, on average, a similar local peak membrane potential at the tuft site of generation because recordings from distal tuft sites revealed that gEPSPs generated in ZD7288 evoked apical dendritic tuft spikes, which boosted their local amplitude (Fig. 4A,B). At the nexus, however, membrane hyperpolarization ensured that gEPSPs failed to reach the absolute peak voltage achieved under control throughout the input-output relationship (Fig. $4 A, B$ ).

Previous work has demonstrated the significant contribution of NMDA receptors to the generation of EPSPs in cortical pyra- midal neurons (Schiller et al., 2000; Losonczy and Magee, 2006; Wang et al., 2008; Larkum et al., 2009; Branco et al., 2010), revealing excitatory synaptic input with a high NMDA to AMPA ratio at apical dendritic tuft and terminal dendritic sites (Otmakhova et al., 2002; Branco et al., 2010; Bittner et al., 2012). We therefore generated gEPSPs by the coactivation of simulated AMPA and voltage-dependent NMDA-receptor-mediated conductance changes (Fig. $4 C$; NMDA: $\tau_{\text {rise }}=0.5 \mathrm{~ms}, \tau_{\text {decay }}=150$ ms; see Fig. 1 for details of voltage dependence; NMDA to AMPA ratio $=1: 1)$. When tuft gEPSPs were generated by AMPA and NMDA EPSGs, the blockade of HCN channels had pronounced excitatory effects; gEPSPs now recruited local apical dendritic tuft electrogenesis, which significantly boosted the peak membrane potential achieved at the site of generation and as signals spread to the nexus of the apical dendritic trunk, despite the large ZD7288-mediated hyperpolarization of the membrane (Fig. 4C,D). A similar excitatory action of ZD7288 was observed when the balance between NMDA and AMPA 

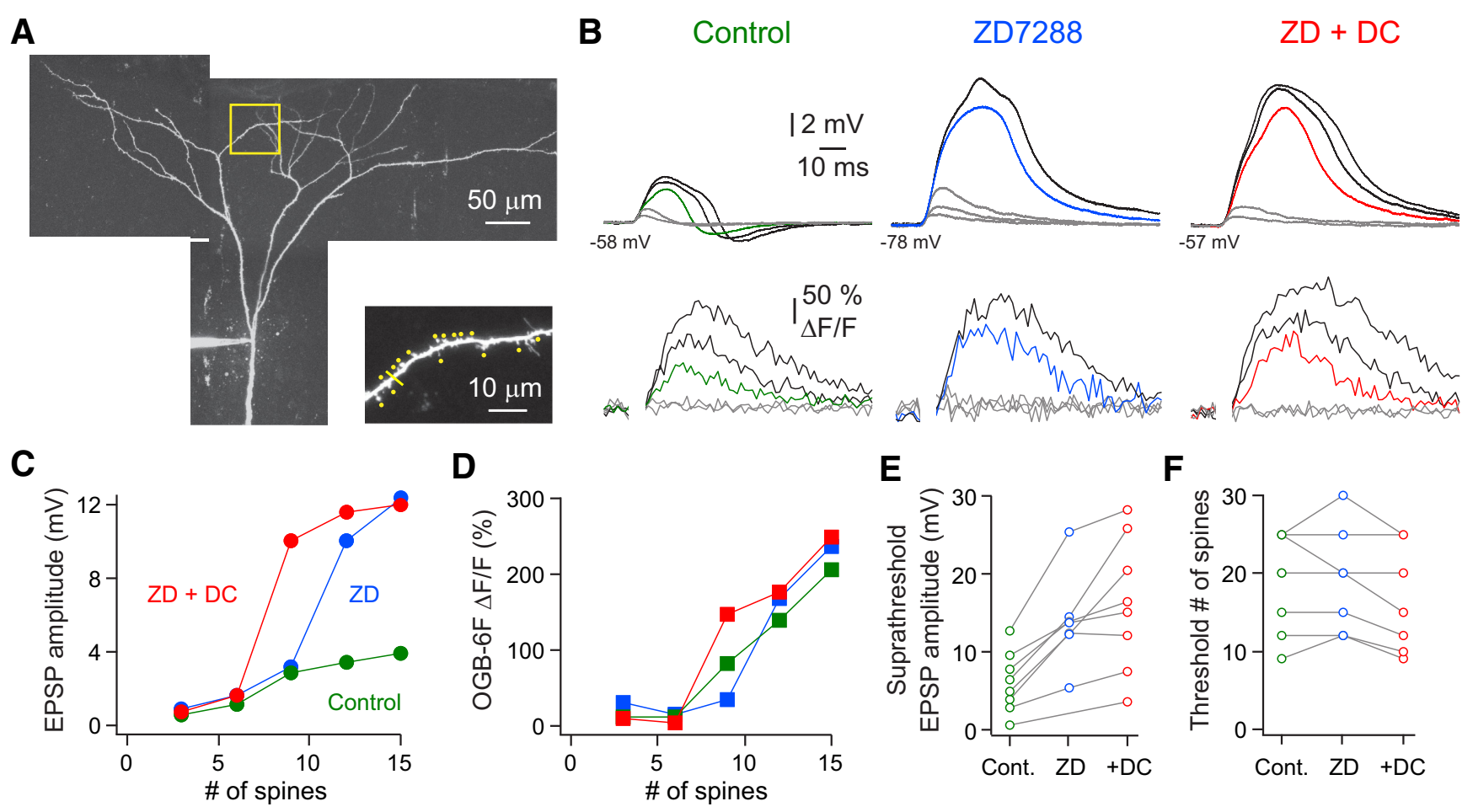

\section{E}
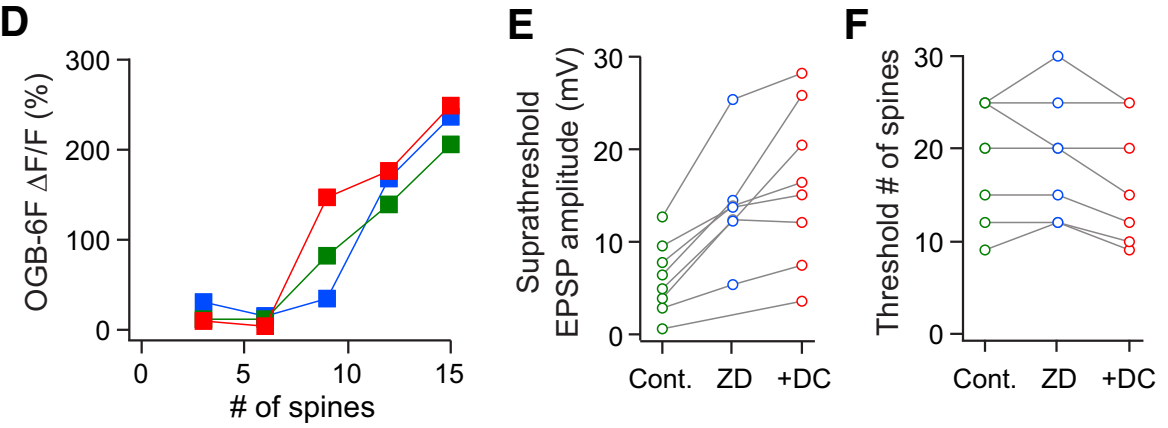

Figure 5. HCN channels regulate the impact of tuft synaptic nonlinearities. $A$, Photomicrograph of the apical dendritic tuft of a layer $5 B$ pyramidal neuron showing the placement of the recording electrode at the nexus of the apical dendritic trunk and the position of the dendritic tuft branch (yellow box) used for multisite 2-photon glutamate uncaging. The positions of uncaging points (yellow symbols) and the branch line scan (yellow line) are shown at higher magnification in the inset. $\boldsymbol{B}$, Families of nexus-recorded voltage responses (top traces) and apical dendritic tuft branch Oregon green BAPTA-6F signals (bottom traces) evoked by near synchronous glutamate uncaging to the head of an increasing number of dendritic tuft spines (shown in $\boldsymbol{A}$, inset) under the indicated conditions. Note the nonlinear increase in the amplitude of voltage and calcium signals. Threshold responses have been illustrated by colored traces, corresponding to the activation of 9 (control, green), 12 (ZD7288, $10 \mu \mathrm{m}$, blue) or 9 spines (ZD7288 + nexus membrane repolarization, ZD + DC, red). C, D, Input- output relationship under the indicated conditions measured by nexus voltage recording $(\boldsymbol{C})$ and apical dendritic tuft branch calcium imaging $(\boldsymbol{D})$. Data from the neuron illustrated in $\boldsymbol{A}$ and $\boldsymbol{B}$. $\boldsymbol{E}$, Summary of the peak amplitude of nexus voltage responses under the indicated conditions, which were accompanied by threshold local calcium signals. $\boldsymbol{F}$, The number of activated spines required to generate suprathreshold nexus voltage and local apical dendritic tuft branch calcium signals under the indicated conditions.

conductance changes was reduced to a ratio of 0.5:1 (data not shown; $n=12$ ).

To investigate the control of synaptic integration by $\mathrm{HCN}$ channels at very distal apical dendritic tuft sites, which are not permissive to direct electrical recording, we used multisite twophoton glutamate uncaging and calcium imaging techniques (Fig. 5; Oregon green BAPTA-6F, $100 \mu \mathrm{M}$ delivered via a nexus whole-cell recording electrode) (Harnett et al., 2013). Fast focal uncaging of MNI-glutamate to the heads of groups of dendritic spines evoked EPSPs (uEPSPs) recorded at the nexus of the apical dendritic trunk (Fig. 5A, B; $0.2 \mathrm{~ms}$ dwell time, $0.1 \mathrm{~ms}$ move time). Input-output relationships, constructed by activating increasing numbers of dendritic spines, revealed the generation of a powerful local excitatory synaptic nonlinearity (Fig. $5 B, C$ ), mediated by NMDA receptors (Larkum et al., 2009; Harnett et al., 2013). When a threshold number of dendritic spines were activated, a large amplitude local apical dendritic tuft branch Oregon green BAPTA-6F signal was generated that increased the amplitude and transformed the time course of uEPSPs recorded from the nexus (Fig. 5B-E). To explore the constraint that HCN channels impose on this form of integration, HCN channels were blocked with ZD7288 $(10 \mu \mathrm{M})$ and the input-output relationship reexamined. The pronounced hyperpolarization of the apical dendritic nexus membrane potential produced by blocking HCN channels (control $=-57.8 \pm 0.4 \mathrm{mV}, \mathrm{ZD} 7288=-79.5 \pm 0.5 \mathrm{mV} ; n=8$ neurons, $n=8$ slices, $n=6$ animals) was accompanied by a significant increase in the amplitude and area of suprathreshold
uEPSPs (Fig. $5 B, C, E$; peak amplitude: control $=6.1 \pm 1.4 \mathrm{mV}$, ZD7288 $=13.91 \pm 2.2 \mathrm{mV}$, paired $t$-test $\mathrm{T}=5.65, p=0.0013$; area: control $=0.094 \pm 0.023 \mathrm{~ms}, \mathrm{ZD} 7288=0.386 \pm 0.058 \mathrm{~ms}$, paired $t$-test $\mathrm{T}=7.002, p=0.0004)$. In contrast to results obtained by the generation of gEPSPs at relatively proximal apical dendritic tuft sites (Fig. 4C,D), the apical dendritic nexus recorded absolute voltage of suprathreshold uEPSPs generated at remote tuft sites were hyperpolarized relative to control conditions and consequently failed to recruit apical dendritic trunk spikes (control = $-51.7 \pm 1.2 \mathrm{mV} . \mathrm{ZD} 7288=-65.1 \pm 2.2 \mathrm{mV}$; site of uncaging $276 \pm 32 \mu \mathrm{m}$ from the nexus recording site; $n=8$ neurons, $n=$ 8 slices, $n=6$ animals). Simultaneous apical dendritic branch calcium imaging, however, revealed that ZD7288 significantly increased the size of dendritic branch Oregon green BAPTA-6F signals imaged close to the site of activated spines (Fig. $5 B, D$; control $=122 \pm 16 \% \Delta F / F, Z D 7288=163 \pm 21 \% \Delta F / F$, paired $t$-test $\mathrm{T}=6.39, p=0.0007 ; n=8$ neurons, $n=8$ slices, $n=6$ animals). These actions were unaccompanied by a significant change in the number of activated spines required to initiate NMDA-receptor-mediated synaptic nonlinearities (Fig. 5B,F). Repolarization of the nexus membrane by the injection of tonicpositive current through the recording electrode did not alter the number of activated spines required to generate apical dendritic tuft synaptic nonlinearities (Fig. 5B, F; ZD7288 + DC: membrane potential $=-59.2 \pm 0.3 \mathrm{mV})$. Notably, repolarization of the nexus membrane potential did not further increase the amplitude of dendritic tuft branch calcium signals (ZD7288 + DC $=$ 
A

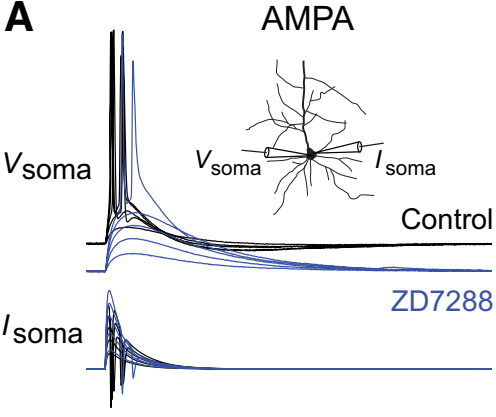

C
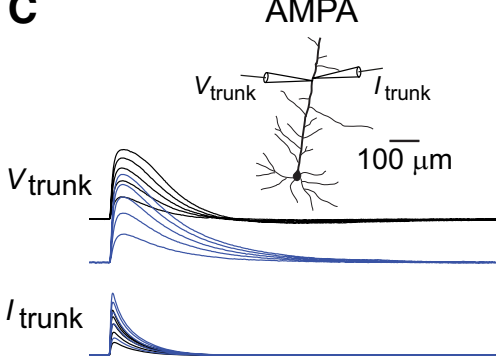

$\mathbf{E}$

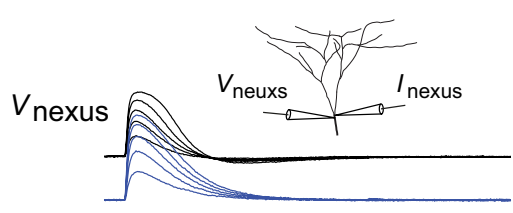

Inexus

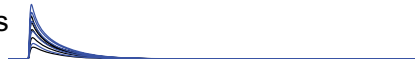

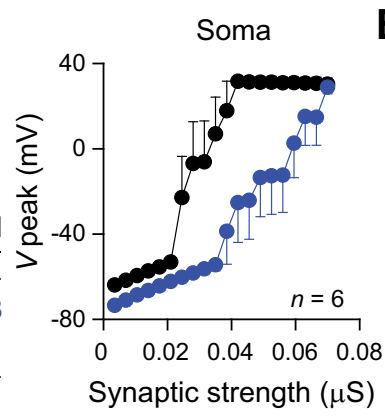

Trunk

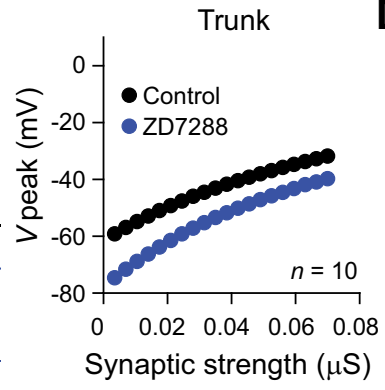

D
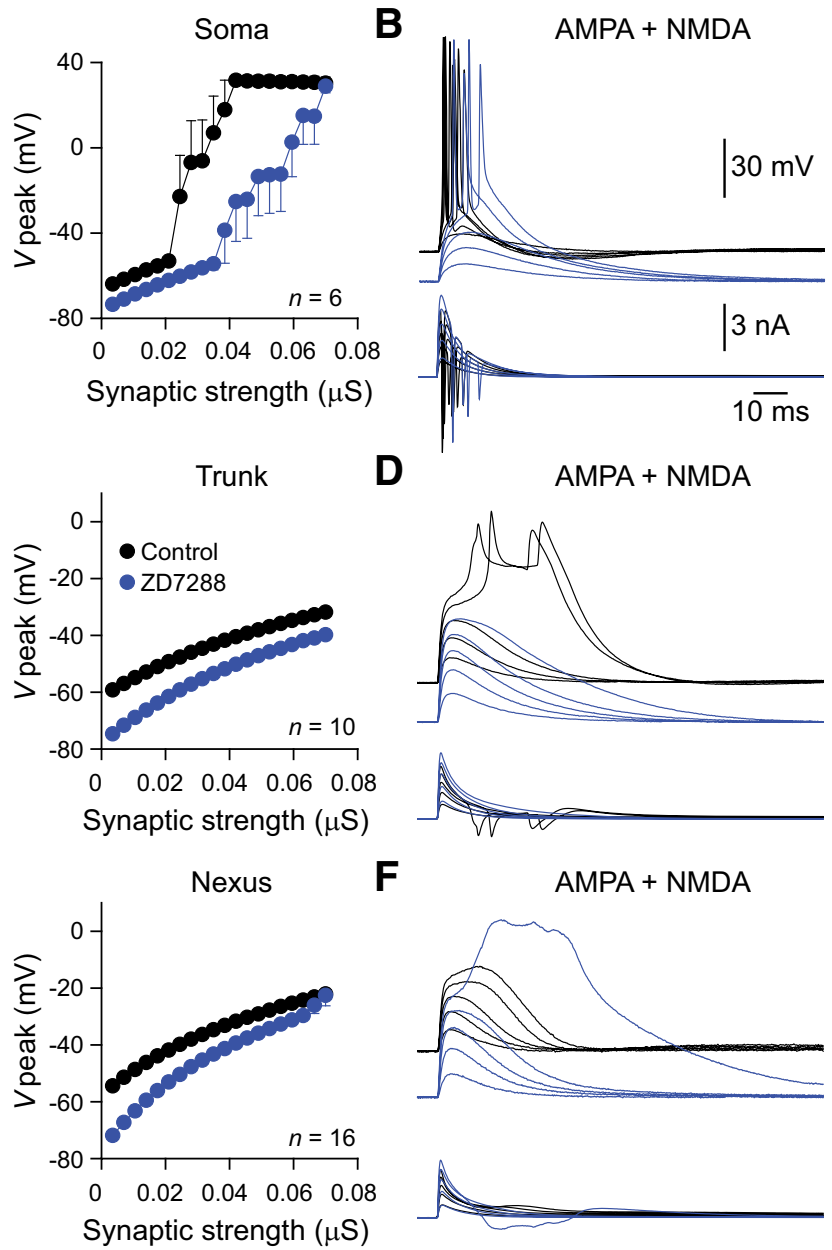

$\mathbf{F}$
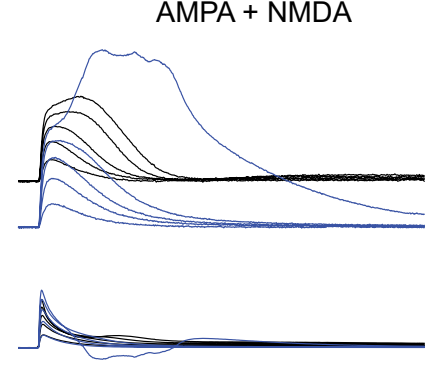
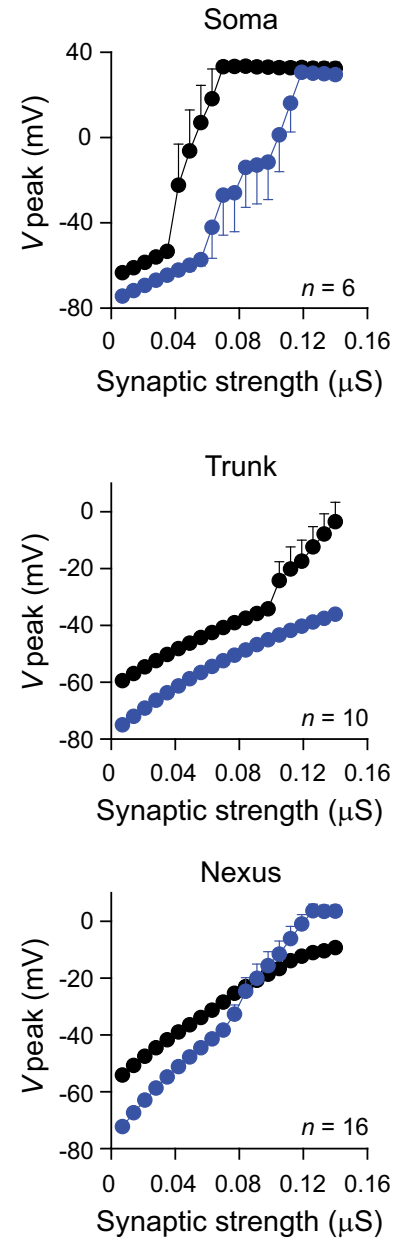

Figure 6. Site-dependent control of excitability by HCN channels. $A, B$, The blockade of HCN channels inhibits somatic excitability. Input- output relationship generated by a family of AMPA ( $A$ ) and AMPA and NMDA ( $\boldsymbol{B}$ ) conductance changes generated and recorded from the soma under control (black traces and symbols) and ZD7288 (10 $\mu \mathrm{M}$, blue traces and symbols). Data have been pooled from $n=6$ neurons. Note the input- output relationship is shifted rightwards in ZD7288. The insets in $A, C$, and $\boldsymbol{E}$ show schematic reconstructions of the recorded neurons. Pooled data are shown as mean \pm SEM. C, $\boldsymbol{D}$, The blockade of HCN channels inhibits apical dendritic trunk excitability. The blockade of HCN channels (ZD7288, $10 \mu \mathrm{m}$, blue traces and symbols) decreases the peak potential ( $V$ peak) reached by gEPSPs generated by AMPA conductance changes $(\boldsymbol{C})$ and inhibits action potential firing evoked by AMPA and NMDA conductance changes $(\boldsymbol{D})$. The illustrated simultaneous recording was made $323 \mu \mathrm{m}$ from the soma. $\boldsymbol{E}, \boldsymbol{F}$, The blockade of $\mathrm{HCN}$ channels has excitatory actions at the nexus of the apical dendritic trunk. Simultaneous apical dendritic nexus recording (722 $\mu \mathrm{m}$ from the soma) demonstrates that the blockade of HCN channels (ZD7288, $10 \mu \mathrm{m}$, blue traces and symbols) decreased the peak potential (V peak) reached by gEPSPs generated by AMPA conductance changes $(\boldsymbol{E})$, but facilitated the generation of dendritic trunk spikes by AMPA and NMDA conductance changes $(\boldsymbol{F})$.

$151 \pm 19 \% \Delta F / F$, paired $t$-test vs $\mathrm{ZD} 7288, \mathrm{~T}=0.05721, p=$ 0.9562; $n=8$ neurons, $n=8$ slices, $n=6$ animals), but did modestly increase the amplitude of nexus recorded suprathreshold uEPSPs (amplitude $=16.1 \pm 3.0 \mathrm{mV}$, paired $t$-test vs ZD7288, $\mathrm{T}=2.545, p=0.0438$ ). Compared with control conditions, however, the absolute nexus voltage achieved by suprathreshold uEPSPs was substantially enhanced when HCN channels were blocked and the nexus membrane potential repolarized ( uEPSP absolute peak voltage $=-43.0 \pm 2.9 \mathrm{mV}$, paired $t$ test vs control, $\mathrm{T}=3.811, p=0.0066, n=8$ neurons, $n=8$ slices, $n=$ 6 animals). Therefore, HCN channels control the amplitude of distal apical dendritic tuft calcium signaling evoked by excitatory synaptic nonlinearities, but do not influence the number of activated apical dendritic tuft spines required for their generation. Furthermore, HCN channels regulated the amplitude and time course of suprathreshold-tuft-generated uEPSPs recorded remotely from the nexus of the apical dendritic trunk, It should be noted, however, that the blockade of HCN channels did not allow the regenerative propagation of synaptically evoked distal apical dendritic tuft electrogenesis to the nexus.

\section{Subcellular control of neuronal excitability}

To determine whether HCN channels uniformly control the excitability of layer 5B pyramidal neurons, we made simultaneous whole-cell recordings from the soma, the proximal apical dendritic trunk, or the nexus and examined the impact that HCN channels have on the input-output relationship generated at each site (Fig. 6). At the soma, the blockade of HCN channels led to a hyperpolarization of the membrane potential and increased the threshold synaptic conductance required to generate action potential firing (Fig. $6 A, B ; n=6, n=6$ slices, $n=5$ animals). At proximal apical dendritic trunk recording sites, the membrane hyperpolarization produced by ZD7288 ensured that gEPSPs failed to reach the threshold for action potential generation (Fig. $6 C, D$; distance from soma $=365 \pm 44 \mu \mathrm{m} ; n=10 ; n=10$ slices; $n=6$ animals). In contrast, at the nexus of the apical dendritic trunk, the membrane hyperpolarization elicited by blocking $\mathrm{HCN}$ channels reduced the peak voltage achieved by gEPSPs evoked by isolated AMPA conductance changes across a broad EPSG range, but revealed the powerful generation of dendritic trunk spikes when gEPSPs were mediated by AMPA and NMDA 
EPSGs (Fig. $6 E, F$; distance from soma $=750 \pm 16 \mu \mathrm{m} ; n=16$, $n=16$ slices, $n=10$ animals). In the presence of ZD7288, AMPA and NMDA EPSGs generated dendritic spikes when the kinetics of the NMDA conductance were varied across a broad range $\left(\tau_{\text {rise }}\right.$ from 0.5 to $5 \mathrm{~ms}$; $\tau_{\text {decay }}$ from 50 to $150 \mathrm{~ms}$; data not shown; $n=8$, $n=8$ slices, $n=5$ animals). Furthermore, it should be noted that, under control conditions, dual apical dendritic nexus recordings revealed that apical dendritic trunk spikes could be evoked in response to the injection of positive ideal current steps with a voltage threshold of $-34.3 \pm 0.5 \mathrm{mV}$, but not by AMPA and NMDA EPSGs, despite gEPSPs reaching a peak voltage of $-11.5 \pm 0.6 \mathrm{mV}(n=39, n=39$ slices, $n=21$ animals $)$. Dynamic conductance-clamp experiments, therefore, suggest that $\mathrm{HCN}$ channels exert excitatory actions at somatic and proximal dendritic trunk sites, but inhibitory actions in the distal apical dendritic arbor (nexus and apical dendritic tuft) when the simulated excitatory input is composed of AMPA- and NMDA-receptormediated components.

In CA1 pyramidal neurons, somatic recording and apical dendritic tuft two-photon calcium imaging has demonstrated that the acute pharmacological blockade or the genetic reduction of HCN channels augments the amplitude and time course of synaptically evoked apical dendritic tuft electrogenesis (Tsay et al., 2007). In CA1 pyramidal neurons, this enhancement has been suggested to be mediated by HCN channel control of the dendritic membrane potential because the augmentation of dendritic tuft electrogenesis could be offset by membrane depolarization provided by raised extracellular potassium (Tsay et al., 2007). To determine directly whether HCN channels control distal dendritic integration in layer 5B pyramidal neurons through a similar voltage-dependent action, we generated families of gEPSPS at the nexus of the apical dendritic trunk under control conditions, in ZD7288, and after the repolarization of the local dendritic membrane potential by the injection of tonic DC current through one of the dendritic recording electrodes (Fig. 7A; nexus NMDA: $\mathrm{AMPA}$ ratio $=1: 1$; injected current $=0.51 \pm 0.02 \mathrm{nA}$; distance from soma $=775 \pm 15 \mu \mathrm{m} ; n=24$ slices, $n=11$ animals). The enhancement of apical dendritic spike generation produced by blocking HCN channels was not annulled by the repolarization of the dendritic membrane potential, but was augmented, decreasing the EPSG required to initiate dendritic trunk spikes (Fig. $7 A, B$, red traces). Similar results were obtained when gEPSPs were generated at apical dendritic tuft sites, where DC repolarization of the membrane potential at the apical dendritic tuft and nexus recording sites enhanced both local tuft dendritic spike generation and the recruitment of apical dendritic trunk spikes (data not shown, $n=10$ ). Therefore, in layer 5B pyramidal neurons, HCN channels do not control distal apical dendritic excitability simply by maintaining a depolarized resting membrane potential.

We therefore investigated whether other facets of the high density of HCN channels in the distal apical dendritic compartment of layer $5 \mathrm{~B}$ pyramidal neurons (Fig. 2) contribute to the control of dendritic spike generation. To examine the impact of conductance, we enhanced the resting conductance at the nexus of the apical dendritic trunk by introducing an excitatory leak conductance using dynamic-clamp techniques, with a reversal potential set to the reversal potential of ensemble $\mathrm{HCN}$ channel activity (reversal potential $=-30 \mathrm{mV} ; \mathrm{g}=19.6 \pm 0.8 \mathrm{nS} ; n=$ 24). The point conductance source lacked the voltage-dependent kinetics of ensemble HCN channel activation/deactivation, but its introduction in the presence of ZD7288 replicated the actions of HCN channels on the control of membrane potential and apparent input resistance at the nexus site of generation (control: $\mathrm{RMP}=-57.1 \pm 0.7 \mathrm{mV}$; peak apparent input resistance $=$ $24.3 \pm 0.7 \mathrm{M} \Omega$; ZD7288 + leak conductance: $\mathrm{RMP}=-56.3 \pm$ $0.7 \mathrm{mV}$; peak apparent input resistance $=24.9 \pm 1.6 \mathrm{M} \Omega$ ). Notably, when the nexus membrane potential was repolarized by the excitatory leak conductance, the recruitment of apical dendritic spikes in response to AMPA and NMDA gEPSPs was abolished, mirroring the actions of $\mathrm{HCN}$ channels (Fig. $7 A, B$, green traces). To dissociate the effects of this conductance from its influence on the membrane potential, the reversal potential of the conductance was set to the resting membrane potential in ZD7288, a procedure that further reduced the peak level of depolarization achieved by gEPSPs (Fig. $7 B$; reversal potential $=-80.2 \pm 0.5$ $\mathrm{mV}, n=13, n=13$ slices, $n=5$ animals). These data suggest that the high density of HCN channels at distal apical dendritic sites supply an excitatory conductance, which acts to depolarize the membrane potential but inhibit apical dendritic tuft and nexus dendritic spike generation, a finding that provides an explanation for the site-dependent excitatory and inhibitory actions of $\mathrm{HCN}$ channels in the dendritic arbor of layer 5B pyramidal neurons.

Because HCN channels are expressed at high density in the distal apical dendritic arbor (Fig. 2) but at low density at somatic and proximal apical dendritic trunk sites of layer $5 \mathrm{~B}$ pyramidal neurons (Williams and Stuart, 2000; Berger et al., 2001; Kole et al., 2006; Kole et al., 2007; Atkinson and Williams, 2009), we reasoned that inhibitory actions in the distal apical dendritic tree are dominated by the local actions of the HCN conductance, but excitatory actions at proximal sites are influenced by the impact that distal HCN channels have on membrane potential. To test this idea, we investigated the control of proximal apical dendritic excitability by manipulating the membrane potential at distal apical dendritic sites, repolarizing the nexus membrane potential in ZD7288 either by the injection of tonic DC current or by the generation of an excitatory leak conductance. Under control conditions, a family of EPSC-shaped current waveforms generated at proximal apical dendritic trunk sites evoked action potential firing (Fig. 7C,D; proximal trunk distance from soma $=426 \pm 28$ $\mu \mathrm{m}$; nexus distance from soma $=752 \pm 34 \mu \mathrm{m} ; n=6 ; n=6$ slices; $n=4$ animals). When HCN channels were blocked by ZD7288, pronounced membrane hyperpolarization ensured that EPSC-shaped current waveforms failed to evoke neuronal output in a manner similar to the HCN channel control of proximal apical dendritic trunk AMPA and NMDA EPSGs (Fig. 6C,D). When the membrane potential of the apical dendritic nexus was repolarized to control values by tonic DC current injection or by an excitatory leak conductance, the membrane potential at proximal apical dendritic sites was repolarized and action potential firing evoked by EPSC-shaped current waveforms was restored (Fig. 7C,D). The generation of an excitatory leak conductance in the distal apical dendritic compartment of layer $5 \mathrm{~B}$ pyramidal neurons, therefore, has dual actions, inhibiting local distal apical dendritic spike generation and augmenting proximal apical dendritic excitability in a manner similar to that of HCN channels.

Consistent with the inhibitory control of distal apical dendritic excitability by HCN channels, two-photon calcium imaging revealed that $\mathrm{HCN}$ channels constrained nexus-current-evoked apical dendritic trunk spike invasion of the apical dendritic tuft (Fig. $8 A, B)$. Under control conditions, dendritic trunk spikes failed to evoke measurable Oregon green BAPTA-6F signals (15 $\pm 2 \%$ $\Delta F / F$ ) at distal apical dendritic tuft sites (Fig. $8 A, B$; imaged at $271 \pm 21 \mu \mathrm{m}$ from the nexus; $n=9$ branches, $n=7$ neurons, $n=$ 7 slices, $n=5$ animals). In ZD7288 $(10 \mu \mathrm{M})$, however, apical dendritic trunk spikes powerfully drove large amplitude den- 
A Control

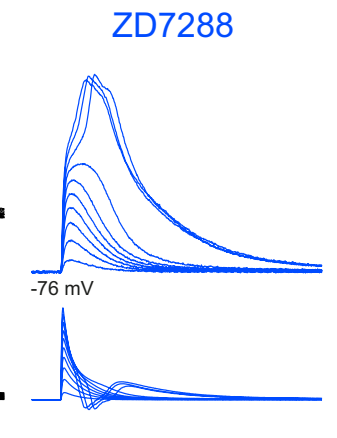

Inexus
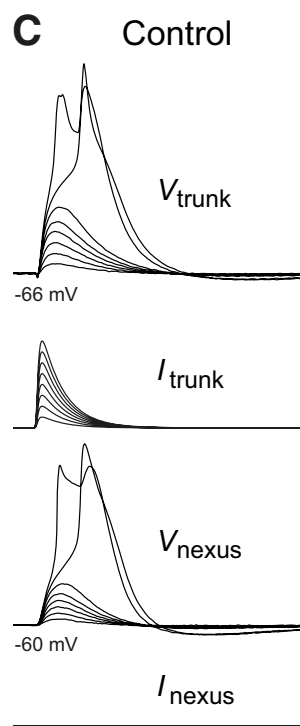

ZD7288
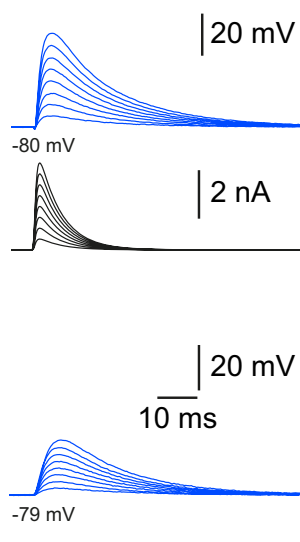

ZD + nexus DC
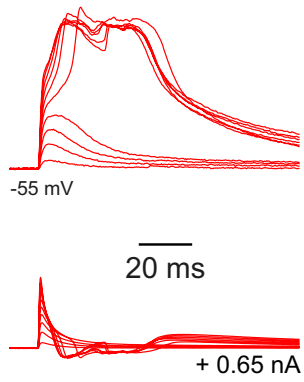
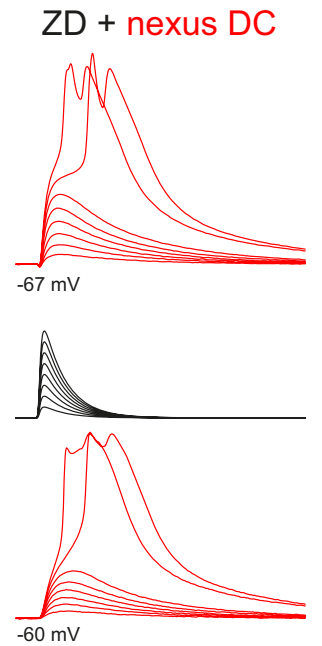

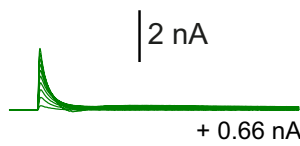

ZD + nexus leak $g$
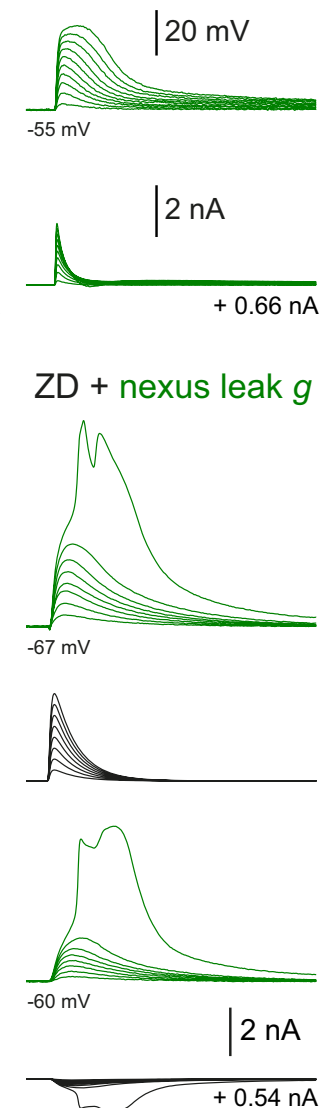
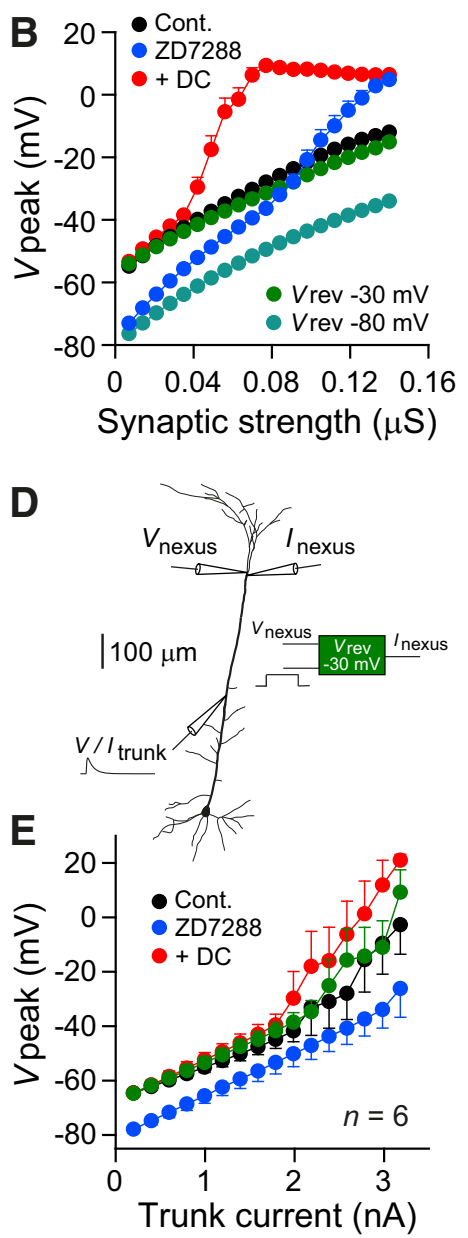

Figure 7. The site-dependent control of excitability is replicated by a distal dendritic excitatory leak conductance. $A$, Simultaneous apical dendritic nexus recording (741 $\mu \mathrm{m}$ from the soma) illustrates families of gEPSPs (top traces) generated by AMPA and NMDA conductance changes (bottom traces, NMDA:AMPA ratio = 1:1) under control conditions, after blockade of HCN channels (ZD7288 $10 \mu \mathrm{M})$, and when the membrane potential was restored to control values by tonic DC current injection (ZD + nexus DC) or by a simulated excitatory leak conductance (ZD + nexus leak $\mathrm{g}$; reversal $=-30 \mathrm{mV}$ ). The value of positive current injected through one of the recording electrodes is indicated. The inset shows a schematic reconstruction of the neuron and placement of recording electrodes. $B$, Pooled input- output relationships show that repolarization of the nexus membrane potential in ZD7288 by the injection of DC current facilitates dendritic spike generation, but repolarization with an excitatory conductance $(V$ reversal $=-30 \mathrm{mV})$ is inhibitory $(n=24)$. Note the inhibitory actions of the leak conductance when the reversal potential is set to the resting potential in ZD7288 $(n=13)$. Conditions are delineated by color, pooled data are shown as mean \pm SEM. C, $\boldsymbol{D}$, Simultaneous apical dendritic trunk (top voltage traces, $423 \mu \mathrm{m}$ from the soma) and nexus (bottom voltage trace, $770 \mu \mathrm{m}$ from the soma) recordings illustrate input-output relationships generated at the proximal recording site in response to a family of EPSC-shaped current waveforms (top current traces) under the indicated conditions (C). Note the hyperpolarized membrane potential and failure to evoke neuronal output in ZD7288 (10 $\mu \mathrm{m}$ ), which was restored by repolarization of the nexus membrane potential by the injection of $D C$ current $(Z D+$ nexus $D C$ ) and by a nexus excitatory leak conductance ( $Z D+$ nexus leak $\mathrm{g}$; reversal $=-30 \mathrm{mV})$. The experimental arrangement is schematically represented in $\boldsymbol{D}$. $\boldsymbol{E}$, Pooled input- output relationships show that repolarization of the nexus membrane potential by the injection of $D C$ current or an excitatory conductance enhances action potential generation in response to the proximal dendritic trunk excitatory input. Conditions are delineated by color as in $\boldsymbol{C}$, pooled data are shown as mean \pm SEM.

dritic tuft calcium signals $(122 \pm 10 \% \Delta F / F)$, consistent with the robust invasion of the apical dendritic tuft (Fig. $8 A, B$, blue traces), a pattern of invasion that was not further enhanced by repolarizing of the nexus membrane (Fig. $8 B ; 134 \pm 10 \% \Delta F / F$ ). Simultaneous recordings from the apical dendritic trunk nexus and tuft sites revealed that the pharmacological blockade of HCN channels significantly decreased the rheobase ideal current required to generate apical dendritic trunk spikes, despite dramatic membrane hyperpolarization (Fig. $8 C$; dual nexus recording: nexus membrane potential: control $=-58.3 \pm 1.1 \mathrm{mV}$; ZD7288 $=-79.1 \pm 1.6 \mathrm{mV} ; \mathrm{ZD} 7288+\mathrm{DC}=-58.7 \pm 0.9 \mathrm{mV}$; rheobase: control $=0.97 \pm 0.08 \mathrm{nA} ; \mathrm{ZD} 7288=0.84 \pm 0.08 \mathrm{nA}$; ZD7288 + DC holding current $=0.45 \pm 0.04 \mathrm{nA}$, step current $=$ $0.40 \pm 0.04 \mathrm{nA}$, total current $=0.85 \pm 0.08 \mathrm{nA}$; control and ZD7288 conditions significantly different ANOVA with Tukey's posttest: $\mathrm{q}=7.63 ; p<0.001 ; n=10)$ and increased the peak amplitude and integral of apical dendritic trunk spikes as they spread into the apical dendritic tuft (Fig. $8 D, E$; average distance from nexus $=112 \pm 13 \mu \mathrm{m} ;$ control $=62.3 \pm 3.3 \mathrm{mV}, \mathrm{ZD} 7288+$ $\mathrm{DC}=75.1 \pm 0.8 \mathrm{mV}$; paired $t$-test, $\mathrm{T}=3.34, p=0.011 ; n=9$ neurons, $n=9$ slices, $n=6$ animals). HCN channels therefore have an inhibitory impact in the distal apical dendritic compartment of layer 5B pyramidal neurons by controlling the ability of excitatory input to generate dendritic trunk and tuft electrogenesis and constraining the spread of subthreshold and suprathreshold voltage responses through the apical dendritic tuft. Because HCN channels are colocalized with $K_{\mathrm{V}}$ channels at apical dendritic tuft sites (Fig. $2 H$ ), we investigated whether the excitability of the apical dendritic tuft is coregulated by these channel classes. After ZD7288 exposure and membrane repolarization, the application of the broad-spectrum $K_{\mathrm{V}}$ channel blocker quinidine $(25 \mu \mathrm{M})$ (Harnett et al., 2013) resulted in a prolongation of 
the time course of dendritic trunk spikes and a dramatic increase of the voltage integral of these events as they spread into the apical dendritic tuft (Fig. 8D,E). Therefore, when $\mathrm{HCN}$ channels are blocked, $K_{\mathrm{V}}$ channels predominately function to regulate the time course of regenerative activity in the distal apical dendritic arbor of layer 5B pyramidal neurons, consistent with a role in controlling the interaction between integration compartments (Harnett et al., 2013).

\section{Discussion}

This study provides the first description of the properties, distribution, and functional impact of native HCN channels in the apical dendritic tuft of neocortical pyramidal neurons. A uniform distribution of $\sim 85 \mathrm{HCN}$ channels $\mu \mathrm{m}^{-2}$ was estimated throughout the tuft, a density similar to that observed from the nexus of the apical dendritic trunk. Because the density of $\mathrm{HCN}$ channels in excised patches reported here is similar to that estimated from cellattached patch-clamp recordings from the distal apical dendritic trunk of layer $5 \mathrm{~B}$ pyramidal neurons when correction for permeability is made (Kole et al., 2007), we conclude that the density of $\mathrm{HCN}$ channels dramatically increases in the apical dendritic trunk with distance from the soma (Williams and Stuart, 2000; Berger et al., 2001; Kole et al., 2006; Kole et al., 2007; Atkinson and Williams, 2009), but plateaus in the apical dendritic tuft. These results contrast with those obtained by antibody labeling of HCN channel subunits in hippocampus, where an increased $\mathrm{HCN}$ channel density in the apical dendritic tuft of CA1 pyramidal neurons was observed (Lörincz et al., 2002; Piskorowski et al., 2011). Our data are, however, supported by recent analysis of the distribution of HCN channels in cellattached patches recorded from the tuft of CA1 pyramidal neurons (Bittner et al., 2012). Disparity between HCN channel density measurements with anatomical and electrophysiological techniques may arise because of the sampling of a smaller membrane area when patches are excised from the thin dendritic branches of the tuft. Simultaneous whole-cell current-clamp recordings from the apical dendritic tuft and nexus, however, revealed a uniform resting membrane potential, compatible with the plateau of HCN channel density, in contrast to the distancedependent depolarization of the membrane between soma and distal apical dendritic trunk sites, which parallels HCN channel expression (Williams and Stuart, 2000; Berger et al., 2001; Kole et al., 2006).

Functional role of $\mathrm{HCN}$ channels in the distal apical dendritic arbor

Simultaneous recording from the apical dendritic tuft and the nexus revealed that $\mathrm{HCN}$ channels have a prominent inhibitory role in the distal apical dendritic tree of layer 5B pyramidal neurons. When HCN channels were blocked, the tuft membrane

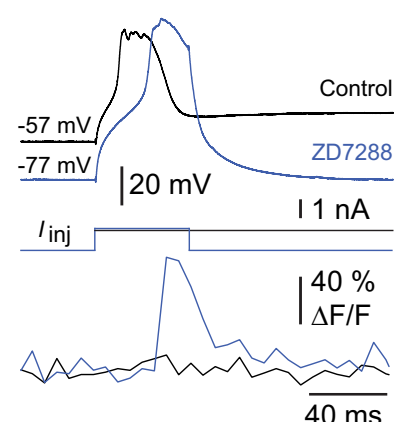

B
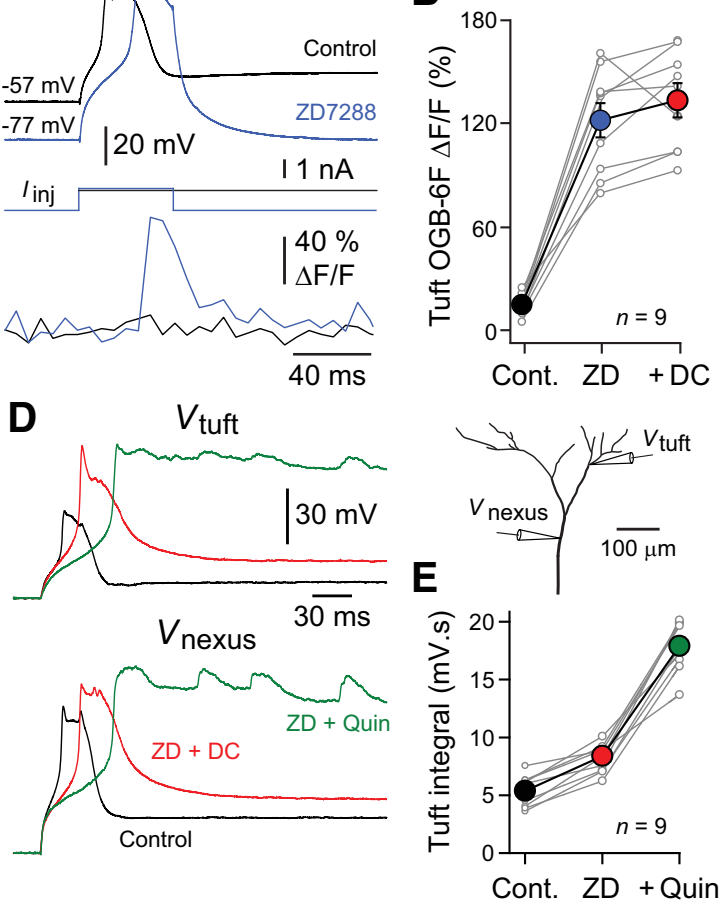

Figure 8. HCN channels control the invasion of apical dendritic trunk spikes into the tuft. $\boldsymbol{A}$, Simultaneous nexus voltage apical dendritic trunk spike (top traces) when HCN channels were blocked with ZD7288 (10 $\mu \mathrm{m}$, blue traces), despite dramatic membrane hyperpolarization. The total injected current was not altered when the membrane was repolarized in ZD7288 (red D, Simultaneous apical dendritic nexus (top traces, $782 \mu \mathrm{m}$ from the soma, $V \mathrm{~m}=-60 \mathrm{mV}$ ) and turt (bottom traces, 954 prolonged apical dendritic trunk spikes. The placement of recording electrodes is shown in the inset. $\boldsymbol{E}$, Pooled data illustrating the integral of apical dendritic tuft voltage responses under the indicated conditions. Large colored symbols represent mean \pm SEM.

hyperpolarized, but apparent input resistance and distancedependent voltage transfer increased, allowing steps of positive current and gEPSPs to drive local dendritic tuft spikes and recruit apical dendritic trunk electrogenesis. Furthermore, HCN channels constrained the amplitude of apical dendritic tuft branch calcium signaling evoked by suprathreshold two-photon glutamate uncaging and regulated the impact of distal apical dendritic tuft NMDA-receptor-mediated synaptic nonlinearities recorded remotely from the nexus of the apical dendritic trunk. In contrast to the delivery of excitatory synaptic input at more proximal apical dendritic tuft sites, synaptically evoked distal apical dendritic tuft electrogenesis did not forward propagate to the nexus to drive apical dendritic spike generation when $\mathrm{HCN}$ channels were blocked. Our recordings indicate that HCN channels do not control the threshold number of activated dendritic tuft spines required to generate these synaptic nonlinearities.

The generation of NMDA-receptor-mediated synaptic nonlinearities in the dendritic arbor is reliant on the voltage-dependent properties of the NMDA-receptor-mediated conductance and the cooperativity between coactivated dendritic spines (Gulledge et al., 2012; Harnett et al., 2012). Our simultaneous recordings reveal that $\mathrm{HCN}$ channels control the amplitude and time course of tuft-generated gEPSPs driven by AMPA and NMDA EPSGs, in- 
dicating that $\mathrm{HCN}$ channels limit the voltage-dependent recruitment of the NMDA conductance. We suggest, therefore, that when HCN channels are blocked, the threshold for the generation of NMDA-receptor-mediated synaptic nonlinearities in the dendritic tuft is preserved because the influence that HCN channels have on the resting membrane potential is balanced by influences on the membrane conductance, the local amplitude of AMPA receptor-mediated EPSPs, and the voltage-dependent recruitment of the NMDA conductance. Furthermore, we find that gEPSPs driven by AMPA and NMDA conductance changes efficiently evoke apical dendritic tuft and trunk spikes only when $\mathrm{HCN}$ channels are pharmacologically blocked, a finding distinct from their robust generation by ideal current (Larkum et al., 1999; Williams and Stuart, 2000; Harnett et al., 2013). We suggest that gEPSPs do not generate apical dendritic trunk or tuft spikes under control conditions because of the concerted influences of HCN channels and the conductance load imparted by the simulated synaptic conductance, injected directly to the dendritic branch, which together prevent the regenerative initiation of dendritic spikes. Consistent with this, when HCN channels were pharmacologically blocked and the membrane potential restored to control values, apparent input resistance was increased, the ideal current required to initiate dendritic spikes was reduced and gEPSPs were capable of generating dendritic spikes.

Previous work has demonstrated that HCN channels control the excitability of the apical dendritic tuft (Tsay et al., 2007; Larkum et al., 2009). In CA1 pyramidal neurons, optical imaging has shown that the pharmacological or genetic reduction of $\mathrm{HCN}$ channel activity augments the magnitude of synaptically evoked apical dendritic tuft calcium electrogenesis (Tsay et al., 2007). Mechanistically, it has been suggested for CA1 pyramidal neurons that the inhibitory control of dendritic tuft excitability by $\mathrm{HCN}$ channels is mediated by their influence on the membrane potential, acting to constrain tuft calcium electrogenesis by determining the availability of a low voltage-activated calcium conductance (Tsay et al., 2007). Consistent with this idea, Tsay et al. (2007) showed that membrane depolarization, evoked by raising the extracellular potassium ion concentration, could act as a proxy for HCN channel activity to annul the augmentation of dendritic tuft calcium electrogenesis. Our direct recordings, however, demonstrate that the augmentation of dendritic tuft and trunk electrogenesis by the pharmacological blockade of $\mathrm{HCN}$ channels in layer $5 \mathrm{~B}$ pyramidal neurons is not annulled, but is instead further enhanced by repolarization of the membrane potential by the injection of tonic DC current through apical dendritic trunk and tuft recording electrodes. Furthermore, we find that when HCN channels are blocked, repolarization of the membrane potential at the base of the apical dendritic tuft (the nexus) does not influence the magnitude of dendritic tuft branch calcium electrogenesis evoked by multisite glutamate uncaging in the distal apical dendritic tuft. Notably, our simultaneous recordings predict that control of the membrane potential at the nexus will powerfully influence the membrane potential at the site of apical dendritic tuft glutamate uncaging because of the modest ( $\sim 20 \%$ ) nexus-to-tuft steady-state voltage attenuation apparent when HCN channels are blocked (Fig. 3C,D). Therefore, in layer $5 \mathrm{~B}$ pyramidal neurons, the calcium conductance that underlies dendritic tuft branch calcium signaling and contributes to apical dendritic trunk spikes is not significantly inactivated at the resting membrane potential, consistent with mediation by highthreshold calcium channels (Pérez-Garci et al., 2013).

\section{Subcellular control of neuronal excitability}

Our results indicate that $\mathrm{HCN}$ channels have dual functional roles in layer $5 \mathrm{~B}$ pyramidal neurons. At distal apical dendritic trunk and tuft sites, we find that HCN channels have predominately inhibitory actions, controlling the initiation and propagation of dendritic spikes. In contrast, at proximal apical dendritic and somatic sites, HCN channels exert excitatory influences by decreasing the threshold excitatory input required to evoke action potential output. We suggest that such compartmentspecific differences arise as a consequence of the subcellular distribution of HCN channels. At distal sites, a high density of $\mathrm{HCN}$ channels controls the local apparent input resistance, time constant, and voltage transfer to sculpt excitatory input. Our results indicate that, despite the pronounced time- and voltagedependent deactivation of HCN channels by membrane depolarization (Williams and Stuart, 2000; Berger et al., 2001; Kole et al., 2006; Kole et al., 2007), a sufficient fraction of HCN channels are available, with reversal potential close to dendritic spike initiation threshold, to control the regenerative recruitment of sodium, calcium, and NMDA receptor channels and so the generation of dendritic supralinearities (Larkum et al., 1999; Kole et al., 2007; Atkinson and Williams, 2009; Harnett et al., 2013; Pérez-Garci et al., 2013). In contrast, at proximal apical dendritic trunk and somatic sites, the low density of HCN channels (Williams and Stuart, 2000; Berger et al., 2001; Kole et al., 2006; Kole et al., 2007) have an excitatory role primarily mediated by the control of membrane potential, an action that is supplemented by the impact that the high density of HCN channels in distal apical dendritic compartments have on the membrane potential at proximal sites. At proximal sites, however, the distributed conductance imparted by HCN channels is relatively low because of the low local HCN channel density and the 'invisibility' of the conductance imparted by distal apical dendritic HCN channels, an effect mediated by the significantly greater spatial compartmentalization of conductance in the dendritic arbor (Williams, 2004). Therefore, at proximal dendritic sites, the differential compartmentalization of voltage and conductance favors excitatory actions mediated by the maintenance of a depolarized membrane potential, whereas at distal sites, the high density of $\mathrm{HCN}$ channels negatively regulates dendritic excitability. Consistent with this idea, we reproduced both the inhibitory actions of $\mathrm{HCN}$ channels on dendritic spike generation at distal apical dendritic sites and the widespread excitatory actions at proximal sites simply by the generation of a point source excitatory leak conductance at the apical dendritic nexus, with a reversal potential identical to that of native HCN channels (Fig. 7). Such a dual action of HCN channels is consistent with the local and global effects of HCN channels on the temporal summation of synaptic potentials revealed by computer simulation (Angelo et al., 2007).

A mixed excitatory and inhibitory action of HCN channels on axosomatic synaptic integration has been previously documented in hippocampal pyramidal neurons (George et al., 2009). In CA1 pyramidal neurons, somatic recordings have revealed that when HCN channels are pharmacologically blocked, the peak voltage obtained by small-amplitude electrically evoked EPSPs was diminished, but as the stimulus strength increased, the peak voltage of EPSPs become more depolarized than under control conditions (George et al., 2009). Experimental findings and computational modeling demonstrated that this effect is mediated by the interaction of EPSPs with a low-voltage $K_{\mathrm{V}}$ conductance, the M current (George et al., 2009), mediated by KV7 channels, which have a predominant axosomatic distribution (Shah et al., 2008). Subsequent computational modeling has, 
however, questioned this interpretation (Migliore and Migliore, 2012). In the distal apical dendritic arbor of layer 5B neocortical pyramidal neurons, we have recently reported a high density of $K_{\mathrm{V}}$ channels, with characteristics similar to $I_{\mathrm{A}}$ and $I_{\mathrm{KD}}$ (Harnett et al., 2013), suggesting that $\mathrm{HCN}$ and $K_{\mathrm{V}}$ conductances may interact to control the initiation of dendritic spikes. The fast activation kinetics, high voltage threshold $(\sim-30 \mathrm{mV})$, and significant voltage- and time-dependent inactivation of the apical dendritic $K_{\mathrm{V}}$ conductance are, however, ill suited to provide the necessary $K_{\mathrm{V}}$ conductance to mediate this action (see analysis of the impact of alterations of theactivation kinetics and voltage dependence of the $K_{\mathrm{V}}$ conductance in George et al., 2009). Rather, our findings indicate that the properties of the $K_{\mathrm{V}}$ conductance in the distal apical dendritic arbor of layer 5 pyramidal neurons is well suited to influence the time course of dendritic spikes and the coupling of axosomatic and apical dendritic integration compartments through regenerative activity (Harnett et al., 2013).

In summary, we find that $\mathrm{HCN}$ channels are ideally distributed and tuned to control the interaction among the apical dendritic tuft, trunk, and axosomatic integration compartments in layer 5B pyramidal neurons (Larkum et al., 1999; Williams, 2005; Harnett et al., 2013), which shape correlation-based integrative operations that underlie the integration of bottom-up intracolumnar input and top-down corticocortical activity during behavior (Xu et al., 2012).

\section{References}

Angelo K, London M, Christensen SR, Häusser M (2007) Local and global effects of $\mathrm{I}(\mathrm{h})$ distribution in dendrites of mammalian neurons. J Neurosci 27:8643-8653. CrossRef Medline

Atkinson SE, Williams SR (2009) Postnatal development of dendritic synaptic integration in rat neocortical pyramidal neurons. J Neurophysiol 102:735-751. CrossRef Medline

Beam KG, Donaldson PL (1983) A quantitative study of potassium channel kinetics in rat skeletal muscle from 1 to 37 degrees C. J Gen Physiol 81:485-512. CrossRef Medline

Berger T, Larkum ME, Lüscher HR (2001) High I(h) channel density in the distal apical dendrite of layer $\mathrm{V}$ pyramidal cells increases bidirectional attenuation of EPSPs. J Neurophysiol 85:855-868. Medline

Bittner KC, Andrasfalvy BK, Magee JC (2012) Ion channel gradients in the apical tuft region of CAl pyramidal neurons. PLoS One 7:e46652. CrossRef Medline

Branco T, Clark BA, Häusser M (2010) Dendritic discrimination of temporal input sequences in cortical neurons. Science 329:1671-1675. CrossRef Medline

Dekker JP, Yellen G (2006) Cooperative gating between single HCN pacemaker channels. J Gen Physiol 128:561-567. CrossRef Medline

Engel D, Jonas P (2005) Presynaptic action potential amplification by voltage-gated $\mathrm{Na}+$ channels in hippocampal mossy fiber boutons. Neuron 45:405-417. CrossRef Medline

George MS, Abbott LF, Siegelbaum SA (2009) HCN hyperpolarizationactivated cation channels inhibit EPSPs by interactions with M-type $\mathrm{K}(+)$ channels. Nat Neurosci 12:577-584. CrossRef Medline

Giocomo LM, Hussaini SA, Zheng F, Kandel ER, Moser MB, Moser EI (2011) Grid cells use HCN1 channels for spatial scaling. Cell 147:11591170. CrossRef Medline

Gulledge AT, Carnevale NT, Stuart GJ (2012) Electrical advantages of dendritic spines. PLoS One 7:e36007. CrossRef Medline

Harnett MT, Makara JK, Spruston N, Kath WL, Magee JC (2012) Synaptic amplification by dendritic spines enhances input cooperativity. Nature 491:599-602. CrossRef Medline

Harnett MT, Xu NL, Magee JC, Williams SR (2013) Potassium channels control the interaction between active dendritic integration compartments in layer 5 cortical pyramidal neurons. Neuron 79:516-529. CrossRef Medline

Harris NC, Constanti A (1995) Mechanism of block by ZD 7288 of the hyperpolarization-activated inward rectifying current in guinea pig substantia nigra neurons in vitro. J Neurophysiol 74:2366-2378. Medline

Harsch A, Robinson HP (2000) Postsynaptic variability of firing in rat cor- tical neurons: the roles of input synchronization and synaptic NMDA receptor conductance. J Neurosci 20:6181-6192. Medline

Hodgkin AL, Huxley AF, Katz B (1952) Measurement of current-voltage relations in the membrane of the giant axon of Loligo. J Physiol 116:424448. Medline

Hussaini SA, Kempadoo KA, Thuault SJ, Siegelbaum SA, Kandel ER (2011) Increased size and stability of CA1 and CA3 place fields in HCN1 knockout mice. Neuron 72:643-653. CrossRef Medline

Jahr CE, Stevens CF (1990) Voltage dependence of NMDA-activated macroscopic conductances predicted by single-channel kinetics. J Neurosci 10:3178-3182. Medline

Kole MH, Hallermann S, Stuart GJ (2006) Single Ih channels in pyramidal neuron dendrites: properties, distribution, and impact on action potential output. J Neurosci 26:1677-1687. CrossRef Medline

Kole MH, Bräuer AU, Stuart GJ (2007) Inherited cortical HCN1 channel loss amplifies dendritic calcium electrogenesis and burst firing in a rat absence epilepsy model. J Physiol 578:507-525. Medline

Larkum ME, Zhu JJ, Sakmann B (1999) A new cellular mechanism for coupling inputs arriving at different cortical layers. Nature 398:338-341. CrossRef Medline

Larkum ME, Nevian T, Sandler M, Polsky A, Schiller J (2009) Synaptic integration in tuft dendrites of layer 5 pyramidal neurons: a new unifying principle. Science 325:756-760. CrossRef Medline

Lavzin M, Rapoport S, Polsky A, Garion L, Schiller J (2012) Nonlinear dendritic processing determines angular tuning of barrel cortex neurons in vivo. Nature 490:397-401. CrossRef Medline

London M, Häusser M (2005) Dendritic computation. Annu Rev Neurosci 28:503-532. CrossRef Medline

Lörincz A, Notomi T, Tamás G, Shigemoto R, Nusser Z (2002) Polarized and compartment-dependent distribution of HCN1 in pyramidal cell dendrites. Nat Neurosci 5:1185-1193. CrossRef Medline

Losonczy A, Magee JC (2006) Integrative properties of radial oblique dendrites in hippocampal CA1 pyramidal neurons. Neuron 50:291-307. CrossRef Medline

Magee JC (1998) Dendritic hyperpolarization-activated currents modify the integrative properties of hippocampal CA1 pyramidal neurons. J Neurosci 18:7613-7624. Medline

Magee JC (1999) Dendritic lh normalizes temporal summation in hippocampal CA1 neurons. Nat Neurosci 2:508-514. CrossRef Medline

Markram H, Lübke J, Frotscher M, Roth A, Sakmann B (1997) Physiology and anatomy of synaptic connections between thick tufted pyramidal neurones in the developing rat neocortex. J Physiol 500:409-440. Medline

Migliore M, Migliore R (2012) Know your current I(h): interaction with a shunting current explains the puzzling effects of its pharmacological or pathological modulations. PLoS One 7:e36867. CrossRef Medline

Milburn T, Saint DA, Chung SH (1995) The temperature dependence of conductance of the sodium channel: implications for mechanisms of ion permeation. Receptors Channels 3:201-211. Medline

Nolan MF, Malleret G, Dudman JT, Buhl DL, Santoro B, Gibbs E, Vronskaya S, Buzsáki G, Siegelbaum SA, Kandel ER, Morozov A (2004) A behavioral role for dendritic integration: HCN1 channels constrain spatial memory and plasticity at inputs to distal dendrites of CA1 pyramidal neurons. Cell 119:719-732. Medline

Nowak L, Bregestovski P, Ascher P, Herbet A, Prochiantz A (1984) Magnesium gates glutamate-activated channels in mouse central neurones. $\mathrm{Na}-$ ture 307:462-465. CrossRef Medline

Nusser Z (2012) Differential subcellular distribution of ion channels and the diversity of neuronal function. Curr Opin Neurobiol 22:366-371. CrossRef Medline

Otmakhova NA, Otmakhov N, Lisman JE (2002) Pathway-specific properties of AMPA and NMDA-mediated transmission in CA1 hippocampal pyramidal cells. J Neurosci 22:1199-1207. Medline

Palmer LM, Shai AS, Reeve JE, Anderson HL, Paulsen O, Larkum ME (2014) NMDA spikes enhance action potential generation during sensory input. Nat Neurosci 17:383-390. CrossRef Medline

Pérez-Garci E, Larkum ME, Nevian T (2013) Inhibition of dendritic Ca2+ spikes by GABAB receptors in cortical pyramidal neurons is mediated by a direct Gi/o-beta-subunit interaction with Cav1 channels. J Physiol 591: 1599-1612. CrossRef Medline

Piskorowski R, Santoro B, Siegelbaum SA (2011) TRIP8b splice forms act in 
concert to regulate the localization and expression of HCN1 channels in CA1 pyramidal neurons. Neuron 70:495-509. CrossRef Medline

Poirazi P, Brannon T, Mel BW (2003) Pyramidal neuron as two-layer neural network. Neuron 37:989-999. CrossRef Medline

Santoro B, Grant SG, Bartsch D, Kandel ER (1997) Interactive cloning with the SH3 domain of $\mathrm{N}$-src identifies a new brain specific ion channel protein, with homology to eag and cyclic nucleotide-gated channels. Proc Natl Acad Sci U S A 94:14815-14820. CrossRef Medline

Santoro B, Lee JY, Englot DJ, Gildersleeve S, Piskorowski RA, Siegelbaum SA, Winawer MR, Blumenfeld H (2010) Increased seizure severity and seizure-related death in mice lacking HCN1 channels. Epilepsia 51:16241627. CrossRef Medline

Schiller J, Major G, Koester HJ, Schiller Y (2000) NMDA spikes in basal dendrites of cortical pyramidal neurons. Nature 404:285-289. CrossRef Medline

Shah MM, Migliore M, Valencia I, Cooper EC, Brown DA (2008) Functional significance of axonal Kv7 channels in hippocampal pyramidal neurons. Proc Natl Acad Sci U S A 105:7869-7874. CrossRef Medline

Sivyer B, Williams SR (2013) Direction selectivity is computed by active dendritic integration in retinal ganglion cells. Nat Neurosci 16:18481856. CrossRef Medline

Smith SL, Smith IT, Branco T, Häusser M (2013) Dendritic spikes enhance stimulus selectivity in cortical neurons in vivo. Nature 503:115-120. CrossRef Medline

Stuart G, Spruston N (1998) Determinants of voltage attenuation in neocortical pyramidal neuron dendrites. J Neurosci 18:3501-3510. Medline

Tsay D, Dudman JT, Siegelbaum SA (2007) HCN1 channels constrain synaptically evoked $\mathrm{Ca} 2+$ spikes in distal dendrites of CA1 pyramidal neurons. Neuron 56:1076-1089. CrossRef Medline
Wang H, Stradtman GG 3rd, Wang XJ, Gao WJ (2008) A specialized NMDA receptor function in layer 5 recurrent microcircuitry of the adult rat prefrontal cortex. Proc Natl Acad Sci U S A 105:16791-16796. CrossRef Medline

Williams SR (2004) Spatial compartmentalization and functional impact of conductance in pyramidal neurons. Nat Neurosci 7:961-967. CrossRef Medline

Williams SR (2005) Encoding and decoding of dendritic excitation during active states in pyramidal neurons. J Neurosci 25:5894-5902. CrossRef Medline

Williams SR, Stuart GJ (2000) Site independence of EPSP time course is mediated by dendritic $\mathrm{I}(\mathrm{h})$ in neocortical pyramidal neurons. J Neurophysiol 83:3177-3182. Medline

Williams SR, Stuart GJ (2002) Dependence of EPSP efficacy on synapse location in neocortical pyramidal neurons. Science 295:1907-1910. CrossRef Medline

Williams SR, Stuart GJ (2003) Voltage- and site-dependent control of the somatic impact of dendritic IPSPs. J Neurosci 23:7358-7367. Medline

Williams SR, Wozny C (2011) Errors in the measurement of voltageactivated ion channels in cell-attached patch-clamp recordings. Nat Commun 2:242. CrossRef Medline

Xu NL, Harnett MT, Williams SR, Huber D, O'Connor DH, Svoboda K, Magee JC (2012) Nonlinear dendritic integration of sensory and motor input during an active sensing task. Nature 492:247-251. CrossRef Medline

Zagotta WN, Olivier NB, Black KD, Young EC, Olson R, Gouaux E (2003) Structural basis for modulation and agonist specificity of HCN pacemaker channels. Nature 425:200-205. CrossRef Medline 